\title{
1 A short prokaryotic argonaute cooperates with membrane effector to confer antiviral
} 2 defense

3 Zhifeng Zeng ${ }^{1,2}$, Yu Chen ${ }^{1,2}$, Rafael Pinilla-Redondo ${ }^{3}$, Shiraz A. Shah ${ }^{4}$, Fen Zhao ${ }^{2,5}$, Chen

4 Wang $^{2,5}$, Zeyu Hu ${ }^{1,2}$, Changyi Zhang ${ }^{6}$, Rachel J. Whitaker ${ }^{6}$, Qunxin She ${ }^{7}$, Wenyuan Han ${ }^{1,2,8}$

$5 \quad{ }^{1}$ State Key Laboratory of Agricultural Microbiology and College of Life Science and

6 Technology, Huazhong Agricultural University, 430070 Wuhan, China

$7 \quad{ }^{2}$ Hubei Hongshan Laboratory, 430070 Wuhan, China

$8{ }^{3}$ Section of Microbiology, University of Copenhagen, Universitetsparken 15, 2100

9 Copenhagen, Denmark

$10{ }^{4}$ Copenhagen Prospective Studies on Asthma in Childhood (COPSAC), Herlev and Gentofte 11 Hospital, University of Copenhagen, Ledreborg Alle 34, 2820 Gentofte, Denmark

$12{ }^{5}$ National Key Laboratory of Crop Genetic Improvement and National Centre of Plant Gene 13 Research, Huazhong Agricultural University, Wuhan 430070, China

$14{ }^{6}$ Carl R. Woese Institute for Genomic Biology, University of Illinois at Urbana-Champaign, 151206 W Gregory Dr, Urbanal, IL 61801, USA.

$16 \quad{ }^{7}$ CRISPR and Archaea Biology Research Center, State Key Laboratory of Microbial

17 Technology, Shandong University, Binhai Road 72, Jimo, 266237 Qingdao, China

$18{ }^{8}$ Lead Contact

19 Correspondence: hanwenyuan@mail.hzau.edu.cn 
22 Summary: Argonaute (Ago) proteins are widespread nucleic acid-guided enzymes that

23 recognize targets through complementary base pairing. While in eukaryotes Agos are

24 involved in RNA silencing, the functions of prokaryotic Agos (pAgos) remain largely unknown.

25 In particular, a clade of truncated and catalytically inactive pAgos (short pAgos) lacks

26 characterization. Here, we reveal that a short pAgo protein in Sulfolobus islandicus, together

27 with its two genetically associated proteins, Aga1 and Aga2, provide robust antiviral protection

28 via abortive infection. Aga2 is a membrane-associated toxic effector that binds anionic

29 phospholipids via a basic pocket, which is essential for its cell killing ability. Ago and Aga1

30 form a stable complex that exhibits RNA-directed nucleic acid recognition ability and directly

31 interacts with Aga2, pointing to an immune sensing mechanism. Together, our results

32 highlight the cooperation between pAgos and their widespread associated proteins,

33 suggesting an uncharted diversity of pAgo-derived immune systems that await to be

34 discovered. 
Argonaute (Ago) proteins are found across all domains of life and comprise a diverse family of defense elements against transposons, plasmids and viruses. Agos bind to short nucleic acid guides that direct the recognition of nucleic acid targets through complementary base-pairing (Hegge et al., 2018; Meister, 2013). Eukaryotic Agos (eAgos) use RNA guides to recognize RNA targets, which are then cleaved by either the eAgo's intrinsic nuclease activity or through the recruitment of ancillary RNA-silencing factors (Hutvagner and Simard, 2008; Ketting, 2011). In contrast, many prokaryotic Ago (pAgo) proteins, including those from Thermus thermophilus (Swarts et al., 2014a), Pyrococcus furiosus (Swarts et al., 2015), Methanocaldococcus jannaschii (Zander et al., 2017) and Clostridium butyricum (Kuzmenko et al., 2020), perform DNA-guided target DNA interference. Previous works have shown that the DNA interference activity is essential for immunity against viruses and plasmids (Kuzmenko et al., 2020; Swarts et al., 2014a). In addition, a recent study reports that $T$. thermophilus Ago is involved in DNA replication completion, expanding the physiological roles of pAgos (Jolly et al., 2020). Some of the DNA-targeting pAgos also exhibit guideindependent DNase activity, which cleaves dsDNA and generates the DNA guides (Swarts et al., 2017; Zander et al., 2017). Comparatively, pAgos from Marinitoga piezophila (Kaya et al., 2016) and Rhodobacter sphaeroides (Miyoshi et al., 2016) use RNA guides to target DNA. Further, a pAgo from Kurthia massiliensis can employ both DNA and RNA guides to target DNA and RNA (Kropocheva et al., 2021; Liu et al., 2021c). Altogether, these studies highlight a remarkable diversity of guide and target preferences for pAgos.

Bioinformatic studies reveal that pAgos encompass substantially more diversity than eAgos (Makarova et al., 2009; Ryazansky et al., 2018). pAgos can be classified into three groups, i.e., long-A, long-B and short. Long- $A$ and long-B pAgo proteins share similar domain architecture with eAgos, containing six structural segments: N-terminal, L1 (Linker 1), PAZ (PIWI-Argonaute-Zwille), L2 (linker 2), MID (Middle) and PIWI (P-element Induced Wimpy Testis) domains. The PIWI domain contains a characteristic RNaseH fold and comprises the nuclease domain. The PIWI domain of long-A pAgos is functionally active, endowing them target cleavage ability and most characterized pAgos belong to this group. Due to their nuclease activity, long-A pAgos have been repurposed for nucleic acid detection (He et al., 2019; Liu et al., 2021b). In contrast, long-B pAgos, represented by Rhodobacter sphaeroides (Rs) Ago, appear to harbor mutations in the cognate catalytic residues that render them inactive nucleases (Kaya et al., 2016). Short pAgo proteins only contain the MID and PIWI domains and, analogous to the long-B group, are inactive nucleases due to mutations within PIWI domain. Currently, the functions and molecular mechanisms driving short pAgos remain unknown.

Interestingly, previous computational analyses have identified many gene families frequently encoded in the genomic neighborhoods of pAgos and diverse protein domains directly fused with pAgos (Makarova et al., 2009; Ryazansky et al., 2018; Swarts et al., 2014b). Although the associated proteins are predicted to be functionally linked with pAgos, little is known about 
their physiological roles and mechanisms of action. In this study, we report that a short pAgo from Sulfolobus islandicus and its associated proteins collaborate to provide robust antiviral immunity by mediating an abortive infection response.

\section{Results}

\section{SiAgo system provides anti-viral defense via abortive infection}

S. islandicus M164 and other related strains (Reno et al., 2009) encode a pAgo protein (M164_1614), which is non-essential for cell viability (Zhang et al., 2018). Analysis of the genetic neighborhood of $M 164 \_1614$ revealed genes commonly associated with mobile genetic elements (Figure S1A), suggesting that the region is mobile or an integration hotspot for horizontally acquired elements. In support of this, the entire region is absent in closely related strains, e.g., in S. islandicus M1425 (Figure S1B). Notably, although the genes in this region vary across $S$. islandicus strains, ago is invariably associated with three other genes i.e., M164_1612, M164_1613 and M164_1615 (Figure 1A, Figure S1A), suggestive of a functional connection. We refer to these syntenic genes as SiAgo system hereafter.

Protein sequence alignment of SiAgo with previously characterized long-A pAgos revealed that SiAgo only contains the MID and PIWI domains (Figure 1A, Figure S1C) and thus belongs to the short pAgo family. Notably, the PIWI domain of SiAgo is mutated, indicating that it lacks nucleic acid target cleavage capabilities (Figure S1C). HHpred analysis (Soding et al., 2005) of the associated proteins suggests $M 164 \_1615$ might play a regulatory role as it contains a HTH DNA binding domain with high similarity to diverse transcription factors (Figure S1D), while M164_1612 and M164_1613 yielded no significant hits to protein domains of known function. In this study, we aimed to investigate the putative coordinated functions of SiAgo, M164_1613 (SiAgo-ạssociated protein1, SiAga1) and M164_1612 (SiAga2).

For this purpose, we expressed SiAgo, SiAga1 and SiAga2 using the pSeSD shuttle vector in S. islandicus E233S1 (Figure 1B), a genetic host derived from S. islandicus Rey15A that does not encode pAgo homologs (Deng et al., 2009). In pSeSD, expression of the genes of interest is driven by an engineered arabinose promoter $\left(\mathrm{P}_{\text {ara }}\right)$ that allows tunable protein expression (Peng et al., 2012). We then infected the strain expressing the SiAgo system (Ago-1-2) and a control strain carrying the empty pSeSD plasmid (CK) with the Sulfolobus SMV1 virus that can infect and replicate in S. islandicus E233S1 (Guo et al., 2019; Uldahl et al., 2016), and assessed culture growth dynamics and viral proliferation post infection (Figure $1 \mathrm{C}$ and D). In the absence of SMV1, expression of Ago-1-2 did not exert an observable effect on culture growth. Upon SMV1 infection at an MOI (multiplicity of infection) of $\sim 2$, the initial growth kinetics of $C K$ were substantially retarded, yet the $\mathrm{OD}_{600}$ (optical density at $600 \mathrm{~nm}$ ) slowly increased up to $\sim 0.4$. In contrast, the growth of the Ago-1-2 strain was almost completely inhibited (Figure $1 C$ ). Measurements of the viral titers in the cultures with plaque forming unit (PFU) assay using a sensitive strain (S. islandicus C1C2)(Uldahl et al., 2016) indicates that 
112 the virus successfully replicated in the CK culture but not in the strain containing the SiAgo

113 system (Figure 1D). Altogether, the data suggest that expression of Ago and its associated

114 proteins inhibits virus proliferation by mediating cell death or dormancy.

115 To gain further insights into the effects of the SiAgo system on SMV1-infected cells, we 116 stained the cell populations with three dyes $\left(\operatorname{DiBAC}_{4}(3)\right.$, DAPI and a mixture of SYTO9 and PI)

117 at different time points post infection. While $\operatorname{DiBAC}_{4}(3)$ is an indicator of the cell membrane

118 depolarization (Bortner et al., 2001; Erental et al., 2012), DAPI stains DNA and indicates

119 cellular DNA content distributions. In contrast, SYTO9 is able to enter live cells with an intact

120 membrane and PI only enters dead cells that have lost membrane integrity (Leuko et al., 2004;

121 Bize et al., 2009). Analysis of the stained cells with flow cytometry indicated that SMV1-

122 infected Ago-1-2 cells started to lose membrane polarity at 3 hpi and that most cells lost

123 membrane polarity at $9 \mathrm{hpi}$, while SMV1 infection did not induce apparent cell membrane

124 depolarization in CK culture at 9 hpi (Figure 1E). Furthermore, infected Ago-1-2 cells were

125 depleted of DNA at $24 \mathrm{hpi}$, whereas the SMV1-infected CK cells showed a similar DNA

126 content distribution to uninfected cells (Figure 1F). At $48 \mathrm{hpi}$, a fraction of the infected CK

127 cells had lost their genomic DNA, while a larger fraction contained more DNA than uninfected

128 cells, suggesting an accumulation of viral DNA and/or suppression of cell division (Guo et al.,

129 2019; Liu et al., 2021a). Finally, SYTO9/PI staining indicated that most infected Ago-1-2 cells

130 lost membrane integrity at $72 \mathrm{hpi}$, in contrast to the much smaller fraction of infected CK cells

131 and in line with the DNA content distribution analysis (Figure 1G). Together, these results

132 indicate that SiAgo system kills infected cells to inhibit viral proliferation.

133 The defense strategy that kills infected cells so that the uninfected clonal cells can grow in a

134 virus-free environment is referred to as abortive infection (Abi) (Isaev et al., 2021; Lopatina et

135 al., 2020). To further investigate whether the SiAgo system confers such a fitness advantage

136 via an Abi response, we transferred the infected cultures into fresh medium at an $\mathrm{OD}_{600}$ of

$137 \sim 0.1$ at $72 \mathrm{hpi}$ and continued to monitor their growth until $172 \mathrm{hpi}$. Indeed, the growth of the

138 strain carrying the SiAgo system was restored after $108 \mathrm{hpi}$ (Figure $1 \mathrm{H}$ ) and less viral

139 particles were observed in comparison to before the transfer (Figure 1I). In agreement with

140 the clearance of infection at this time point, flow cytometry analysis revealed that a

141 considerable fraction of cells showed similar DNA content distributions to uninfected cells

142 (Figure 1J). The data confirm that SiAgo system allows the cell culture to successfully clear

143 the viral infection and restore a population of virus-free cells. In contrast, the CK culture

144 displayed long-lasting slow growth kinetics and continued to exhibit high-titer virus particles.

145 The DNA content distributions of the CK culture were also similar to those before the transfer,

146 indicating that SMV1 maintains a stable infectious status in the cells instead of inducing cell

147 lysis, in line with previous studies on SMV1 and other Sulfolobus viruses (Guo et al., 2019;

148 Liu et al., 2021a; Prangishvili et al., 2006; Uldahl et al., 2016).

149 Defense requires all three proteins and SiAga2 is the toxic effector 
150 To investigate how the SiAgo system performs Abi, we firstly analyzed the minimum

151 components required for the process. We constructed strains expressing combinations of only

152 two of the three proteins, i.e., Ago-Aga1, Ago-Aga2 and Aga1-Aga2. The corresponding

153 strains, as well as the strains containing empty vector (CK) and expressing all three

154 components (Ago-1-2), were subjected to SMV1 infection and subsequent phenotypic

155 analysis. Importantly, the results show that lack of any one of the three components abolished

156 DNA depletion in cells and resulted in successful viral proliferation (Figure 2A and B),

157 highlighting that all three proteins are essential for the execution of the Abi response.

158 In order to mediate anti-viral protection, Abi defense systems must include a sensor module

159 and a killer module (Lopatina et al., 2020); the former senses viral infection and activates the

160 latter to induce cell toxicity. First, we sought to reveal which of the three protein components

161 is the toxic effector. To address this question, we analyzed whether overexpression of any of

162 the proteins would induce cell toxicity. Each of the three proteins was expressed using the

$163 P_{\text {ara }}$ promoter and the expression strains were cultured in media containing either sucrose

164 (Suc) or arabinose (Ara), the latter of which can greatly induce the expression of the proteins

165 of interest (Peng et al., 2012). In the Suc medium, the growth of the three strains was similar

166 to the CK strain (Figure 2C, Figure S2A). However, while in the Ara medium the strains

167 expressing SiAgo or SiAga1 showed normal growth kinetics, overexpression of SiAga2

168 resulted in significant growth retardation, indicative of its toxicity (Figure 2C, Figure S2A).

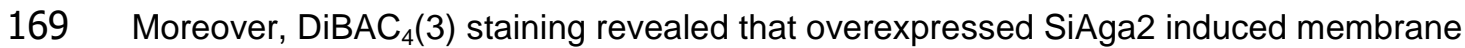

170 depolarization (Figure 2D). On the other hand, even co-overexpression of SiAgo and SiAga1

171 did not exhibit any inhibition on culture growth, further reinforcing the notion that SiAga2 is the

172 effector of SiAgo system and can perform cell toxicity independently.

\section{SiAga2 binds to anionic head groups of phospholipids}

174 Next, we sought to explore the molecular mechanisms underlying the SiAga2-mediated Abi 175 antiviral immune response. Analysis of the protein sequence using TMHMM server (Krogh et

176 al., 2001) indicated that SiAga2 contains two transmembrane regions (2xTM) (Figure 3A). We

177 subsequently confirmed that SiAga2 is a membrane-associated protein with fluorescence in

178 situ hybridization in vivo (Figure 3B). Then, we predicted the protein structure of SiAga2

179 leveraging the AlphaFold2 structure prediction pipeline (Jumper et al., 2021) (Figure 3C). The

180 results indicate that the soluble domain of SiAga2 contains a basic pocket facing the

181 membrane. We hypothesized that such a domain architecture could be responsible for

182 mediating the interaction with the anionic head groups of membrane lipids (Cho and Stahelin,

183 2005). To this end, we expressed SiAga2 $\Delta C$ (lacking $2 \times T M$ ) and screened for potential

184 targets using commercial strips carrying a panel of immobilized lipids. Noticeably, the

185 membrane lipids of archaea are significantly different from their bacterial and eukaryotic

186 counterparts, particularly in the carbon chains, the bound linking carbon chains and glycerol,

187 and the position of phosphate group on glycerol (Lombard et al., 2012). However, the head

188 groups of membrane lipids are shared across the three domains of life. Specifically, the head 
groups of Sulfolobus include inositol, ethanolamine and glycerol (Koga and Morii, 2005), all of which are included in the tested lipids.

191 The strip binding screening revealed that SiAga2 $\Delta \mathrm{C}$ strongly bound to phosphatidic acid (PA) and the lipids containing phosphorylated phosphoinositide (phosphatidylinositol (n)-phosphate,

$193 \mathrm{PI}(\mathrm{n}) \mathrm{P})$, and exhibited lower affinity to cardiolipin and phosphatidylserine (PS) (Figure 3D).

194 Comparison of the affinitive and non-affinitive lipids indicated two apparent rules dictating 195 substrate preference for SiAga2 $\triangle \mathrm{C}$ (Figure S3). First, the phosphate group is important, as 196 indicated by the comparison of the PI(n)P and phosphatidylinositol (PI) (Figure S3A), and the comparison of PA and diacylglycerol (DAG) (Figure S3B). Phosphatidylcholine (PC),

198 phosphatidylethanolamine (PE), and phosphatidylglycerol (PG) are not bound probably

199 because their phosphate group is covered by other moieties. Second, SiAga2 $\Delta C$ binds to

200 phospholipids instead of lysophospholipids, since sphingosine 1-phosphate (S1P) and

201 lysophosphatidic acid (LPA) (which contain a free phosphate group), are non-affinitive lipids

202 (Figure S3C).

\section{The basic pocket of SiAga2 is essential for mediating Abi and binding anionic}

204 phospholipids

We further explored the functional implications of the identified basic pocket. To analyze whether the pocket is important for mediating Abi, we constructed strains expressing versions of the SiAgo system where SiAga2 contains substitution mutations of the alkaline residues predicted to be within or close to the pocket, i.e., R7A-R8A (M1), K12A-K13A (M2) and R7AR8A-K12A-K13A (M3) (Figure 4A). Analysis of the response of the strains to SMV1 infection indicates that mutation of $\mathrm{R} 7-\mathrm{R} 8$ and $\mathrm{K} 12-\mathrm{K} 13$ significantly impaired membrane depolarization, while mutation of the four residues (tetramutation) abolished the phenomenon entirely (Figure

212 4B). In support of this, the DNA content distributions of the tetramutation strain were similar to 213 that of the CK strain lacking the SiAgo system, indicating that the tetramutation abolished

214 DNA loss (Figure 4C). Moreover, the tetramutation also lost the inhibition of viral proliferation,

215 while each dimutation moderately impaired the inhibition of viral proliferation (Figure 4D).

216 Together, the data indicate that the basic pocket in SiAga2 is essential for mediating Abi. To

217 further analyze whether the mutations would affect the affinity of SiAga2 $\Delta \mathrm{C}$ to lipids, we

218 expressed the corresponding SiAga2 $\Delta \mathrm{C}$ mutants and analyzed their affinity to the membrane 219 strip. The results showed that each dimutation largely impaired the affinity to PA and PI(n)Ps, 220 and that the tetramutation almost abolished the lipid binding ability (Figure 4E), indicating that 221 the basic pocket is indeed involved in binding to the anionic head groups of phospholipids.

\section{SiAgo and SiAga1 interact with SiAga2 and enhance its toxicity}

223 Given that SiAga2 is the sole toxic protein, we propose that SiAgo and SiAga1 are likely 224 implicated in the sensor module in the Abi process. To gain insights into the functions of these 225 two proteins, we compared the phenotypes of the strains expressing Aga2 or co-expressing 
226 Ago-1-2 in the Ara medium. The results show that, although overexpression of SiAgo and

227 SiAga1 exerted little effects on culture growth or membrane polarity, co-overexpression of

228 Ago-1-2 resulted in slower culture growth and more membrane-depolarized cells than

229 overexpression of SiAga2 alone (Figure 5A and B, Figure S2B). The data therefore indicate

230 that overexpressed SiAgo and SiAga1 enhance the toxicity of SiAga2 in the absence of viral

231 infection.

232 Signal transduction from sensing viral infection to the activation of the toxic effector requires a

233 specific interplay between the sensor and killer modules. To reveal possible interactions

234 between SiAgo, SiAga1 and SiAga2, the three proteins were co-expressed together or in

235 pairs in E. coli, or expressed independently as controls. In the co-expression strains, only one

236 protein was labeled with a $6 \times \mathrm{His}$ tag and used as the bait during purification in order to check

237 whether the other proteins were co-eluted. Full length SiAga2 was expressed as a fusion with

238 the maltose binding domain (MBP) to increase its stability. The purification procedure

239 included Ni-NTA chromatography, anion exchange chromatography and size exclusion

240 chromatography (SEC). During SEC, the elution volume of SiAga1 and SiAgo was about 16.1

241 and $15.0 \mathrm{~mL}$ respectively. MBP-fused SiAga2 was eluted at $\sim 8.6 \mathrm{~mL}$ even though the sample

242 has been treated with detergent, indicative of a large protein aggregate (Figure 5C, Figure

$243 \mathrm{~S} 4 \mathrm{~A} \sim \mathrm{C})$. Purification of co-expressed His-Ago+Aga1 resulted in a single peak containing both

244 proteins at about $14.5 \mathrm{~mL}$ (Figure 5D, Figure S4D), indicative of a stable complex. Estimation

245 of the stoichiometry of the two proteins suggests a 1:1 ratio in the complex (Figure S4E and

246 F). In addition, MBPAga2 was co-purified with His-Ago and His-Aga2, respectively, resulting

247 in that a fraction of His-Ago and His-Aga2 was eluted at around $8.5 \mathrm{~mL}$ (Figure 5D, Figure

248 S4G and H). Similarly, purification of co-expressed His-Ago+Aga1+MBPAga2 yielded a single

249 peak at $\sim 8.2 \mathrm{~mL}$, which contains all the three proteins (Figure 5E, Figure S4I). As negative

250 control, purification of co-expressed His-Ago+Aga1+MBP did not obtain MBP (Figure 5E,

251 Figure S4J), excluding the possibility that His-Ago+Aga1 interacts with MBP. Together, the

252 data indicate that the three components interact with each other in pairs and can form a

253 ternary complex.

254 To reveal how they interact with each other in the native host, we expressed and purified the

255 three proteins from Sulfolobus cells using His-tagged SiAgo as the bait. SEC results indicate

256 that the co-purification resulted in a peak at $\sim 14.5 \mathrm{ml}$, representing the His-Ago+Aga1

257 complex and a small peak at $\sim 8.2 \mathrm{~mL}$ containing all the three proteins (Figure $5 \mathrm{~F}$, Figure

$258 \mathrm{~S} 4 \mathrm{~K} \sim \mathrm{N})$. The data reinforce the conclusion that the three proteins form a ternary complex and

259 support that SiAgo and SiAga1 form a complex in the cytoplasm, which are then recruited to

260 SiAga2 in the native host (Figure 5G).

\section{Guide and target binding of Ago-Aga1 complex}

262 Ago proteins are inherently directed by nucleic acid guides to bind and/or cleave

263 complementary nucleic acid targets. We thus predicted that the nucleic acid recognition ability 
264 is important for the function of the SiAgo system. To shed light on how SiAgo binds to nucleic

265 acids, we first performed an electrophoretic mobility shift assay (EMSA) using single strand

266 RNA and DNA substrates. Because the 5' group of the guide strand can affect the recognition

267 by Ago proteins (Kaya et al., 2016; Ma et al., 2005; Miyoshi et al., 2016; Parker et al., 2005),

268 we used both substrates containing a 5' phosphorylate (5P) group and a 5' hydroxyl group

$269(5 \mathrm{OH})$, respectively. SiAgo showed weak but apparent binding ability to RNA and the

270 preferred substrate is 5P-RNA (Figure S5A). Considering SiAgo and SiAga1 form a complex,

271 we further analyzed the nucleic acid binding ability of the SiAgo-Aga1 complex. The complex

272 showed higher affinity to all tested nucleic acids, compared to SiAgo alone (Figure 6A and B),

273 indicating that SiAga1 assists SiAgo to bind nucleic acid. However, SiAga1 itself did not show

274 detectable binding affinity to any tested nucleic acids (Figure S5B). In addition, the SiAgo-

275 Aga1 complex still preferred 5P-RNA substrates, suggesting that the SiAgo-Aga1 complex

276 uses 5P-RNA as the guide strand (Figure 6A and B).

277 Next, we analyzed whether the SiAgo-Aga1 complex possesses guide RNA-directed target

278 nucleic acid recognition ability. The complex was incubated with 5P-RNA at the ratio of 4:1,

279 when most RNA was associated with the complex. Then, the ternary complex was further

280 incubated with nucleic acids that are complementary to guide RNA (TDNA and TRNA) or not

281 (NTDNA and NTRNA). The results show that only the complementary DNA and RNA were

282 efficiently bound by the ternary complex (Figure 6 C). Further, addition of 20 -fold unlabeled

283 complementary competitors abolished the binding to target nucleic acids, while non-

284 complementary competitors exhibited little effects on the target binding (Figure 6C). The data

285 show that preloading of 5P-RNA endows SiAgo-Aga1 complex with the specific target

286 recognition ability.

287 MID domain is important for both Abi induction and target recognition

288 The MID domain of pAgos is implicated in binding to the 5' end of the guide. Mutation of the 289 conserved residues of MID domain impairs the guide binding ability and the target silence or 290 cleavage activity (Ma et al., 2005; Miyoshi et al., 2016; Willkomm et al., 2017). SiAgo harbors 291 the conserved MID domain residues as other pAgos (Figure S1C). To analyze whether 292 mutation of the conserved residues would affect target recognition of SiAgo-Aga1 complex, 293 we purified SiAgo-Aga1 complexes carrying a point mutation within the MID domain, either 294 K142A (M1) or K183A (M2), respectively. EMSA analysis indicated that the wild type and 295 mutated complexes showed similar affinity to the 5P-RNA guide (Figure S5C). Next, the 296 complexes were preloaded with guide RNA and analyzed for their affinity to target DNA. The 297 mutated complex still bound target DNA, but the binding resulted in two bands, one of which 298 was similar to that of the wild type complex, while the other band migrated faster in the gel, 299 indicative of a different form of the target-binding complex (Figure 7A). In addition, a band 300 representing the duplex of target DNA and guide RNA was observed for the mutated 301 complexes in the presence of 20-fold non-complementary competitor (NTDNA), suggesting 302 that guide RNA has been released from the mutated complexes. To further explore this 
303 phenomenon, we preloaded the complexes with FAM-labeled guide RNA and incubated the

304 ternary complexes with complementary DNA (TDNA), non-complementary DNA (NTDNA), or

305 both. Incubation with the DNA resulted in release of guide RNA from the complexes, and

306 more RNA was released from the mutated complexes than the wild type complex (Figure 7B

307 and $\mathrm{C}$ ), indicating that the conserved residues play a role in stabilizing the binding to guide

308 RNA.

309 Next, we analyzed whether the conserved MID residues are important for Abi induction of the

310 SiAgo system. We therefore constructed strains expressing the SiAgo system carrying the

$311 \mathrm{~K} 142 \mathrm{~A}$ and K183A mutations of SiAgo and analyzed the response of the strains to SMV1

312 infection. The mutated SiAgo system failed to induce $\operatorname{DiBAC}_{4}(3)$-positive cells and resulted in

313 similar DNA content distributions to the strain lacking the system (Figure 7D and E), indicating

314 that mutation of MID domain abolishes the Abi induction ability of the SiAgo system.

315 Subsequent PFU analysis showed that the viral titer of the strains carrying the mutated SiAgo

316 system was about 100 times higher than that of the WT system, but still substantially lower

317 than the strain lacking the system (Figure 7F). The data suggest that the mutated SiAgo

318 system can still moderately impair SMV1 release and/or replication by an unknown

319 mechanism. 


\section{Discussion}

322 In this study, we demonstrate that a short pAgo and its two genetically associated proteins

323 (Aga1 and Aga2), mediate an Abi response that confers robust anti-viral immunity in $S$.

324 islandicus. Abi is a defense strategy employed by many prokaryotic defense systems (Isaev

325 et al., 2021; Lopatina et al., 2020) and is composed of three steps: (1) a sensor module

326 recognizes a cue from an invading virus; (2) the sensor module activates a toxic effector

327 (killer module); (3) the effector module induces cellular dormancy or cell death, hence

328 preempting further viral spread in the population. In our study, the cells containing the SiAgo

329 system sequentially experienced membrane depolarization, loss of genomic DNA and loss of

330 membrane integrity post viral infection. The data suggest that SiAgo system directly induces

331 membrane depolarization, which eventually results in cell death. Notably, S. islandicus M164,

332 which naturally carries the SiAgo system, turns into a dormant status post viral infection

333 (Bautista et al., 2015). The status is either reversible with active CRISPR-Cas immunity or

334 results in cell death in the absence of CRISPR-Cas immunity. We cannot exclude the

335 possibility that the SiAgo system may mediate the cellular dormancy in S. islandicus M164

336 and provide immunoprotection in cooperation with CRISPR-Cas systems.

337 In the SiAgo system, the SiAgo-associated protein SiAga2, which is a membrane-associated

338 protein, acts as the killer effector. Membrane proteins are widely found in CBASS (Millman et

339 al., 2020b), retrons (Mestre et al., 2020; Millman et al., 2020a), type III CRISPR-Cas (Shah et

340 al., 2019; Shmakov et al., 2018), Thoreis, Zorya, Kiwa, etc. (Doron et al., 2018) and are

341 predicted to function as toxic effectors. Notably, in addition to SiAga2, the gene contexts of

342 pAgos encode other membrane proteins as well (Ryazansky et al., 2018). Previous

343 bioinformatic analyses show that SIR2 and TIR domains, which are recently found to be

344 implicated in Abi (Ofir et al., 2021), are also found in association with pAgos, especially short

345 pAgos (Ryazansky et al., 2018). Conceivably, pAgo systems could rely on these putative

346 ancillary effector proteins (or domains) to mediate immunity, highlighting Abi as a common

347 strategy for a broad diversity of pAgo systems, especially those lacking intrinsic nuclease

348 activity.

349 Our findings demonstrate that SiAga2 mediates cell death via membrane depolarization, a

350 phenomenon that has been observed for other Abi systems containing toxic membrane

351 effectors. These effectors are believed to form ion channels or pores that allow free flux of

352 ions or other cellular contents across the cell membrane and result in loss of membrane

353 potential (Duncan-Lowey et al., 2021; Durmaz and Klaenhammer, 2007; Parma et al., 1992).

354 Intriguingly, a similar strategy is also employed by eukaryotes to mediate programmed cell

355 death, including apoptosis, necroptosis and pyroptosis (Ly et al., 2003; Shi et al., 2017; Wang

356 et al., 2014). Moreover, SiAga2 relies on its binding to the anionic head groups of

357 phospholipids to mediate cell death. The characteristic is also shared by many mammal cell-

358 suicide effectors, such as gasdermin, a pore-forming protein which mediates pyroptosis in

359 response to microbial infection (Ding et al., 2016; Liu et al., 2016), and MLKL, a necroptosis 
360 effector (Dondelinger et al., 2014; Wang et al., 2014). In addition, SiAga2 forms large

361 oligomers, which is a common feature for pore-forming proteins (Mesa-Galloso et al., 2021).

362 These similarities reveal an unprecedented parallel between archaeal and mammalian cell-

363 suicide immune pathways. Notably, gasdermins have been recently identified in bacteria and

364 shown to form toxic membrane pores (Johnson et al., 2021), further highlighting membrane

365 disruption-mediated cell death as a common immune response mechanism across the three

366 domains of life.

367 The present study raises a question: what is the native target of SiAga2? In vitro, SiAga2

368 exhibits the highest affinity to $\mathrm{PA}$ and $\mathrm{PI}(\mathrm{n}) \mathrm{P}$, the archaeal counterparts of which are 2,3-di-O-

369 geranylgeranylglyceryl phosphate (DGGGP) and archaetidylinositol phosphate (AIP),

370 respectively. DGGGP and AIP are not the inherent components of the cell membrane but

371 intermediates in lipid synthesis (Jensen et al., 2015; Rastadter et al., 2020). A possible

372 scenario is that SiAga2 binds the intermediates and retains them from further lipid synthesis

373 reactions. In addition, cardiolipin and PS, the less affinitive substrate of SiAga2, only have

374 their counterparts in euryarchaea instead of crenarchaea. Together, the results imply that

375 DGGGP and AIP could serve the potential targets of SiAga2 in vivo. Further investigations of

376 the interaction between SiAga2 and its targets are required to provide insights into the

377 membrane disruption mechanisms of this unique archaeal toxic effector.

378 We demonstrate that SiAgo and SiAga1 form a stable complex that exhibits RNA-guided

379 nucleic acid recognition ability. SiAga1 significantly contributes to nucleic acid binding,

380 suggesting that it may complement the loss of the $\mathrm{N}$-terminal and PAZ domains in SiAgo,

381 which function in guide and target binding in long pAgos (Kaya et al., 2016; Ma et al., 2004;

382 Song et al., 2004). Other short pAgos have been found to be fused or associated with APAZ

383 domain and/or DNA binding domains (Ryazansky et al., 2018), which might also contribute to

384 guide and target binding.

385 The MID domain of pAgos functions in interacting with the 5'-end of guides (Ma et al., 2005;

386 Miyoshi et al., 2016; Willkomm et al., 2017). In the SiAgo-Aga1 complex, the conserved

387 residues in the MID domain can stabilize the association of guide RNA with the complex, and

388 thus facilitate target binding. Moreover, we show that the conserved residues are essential for

389 mediating Abi, indicative of the importance of nucleic acid recognition in the process. In

390 addition, the SiAgo-Aga1 complex interacts with SiAga2 and can enhance its toxicity. Based

391 on these results, we propose a model that explains how the SiAgo system mediates Abi

392 (Figure 8): the SiAgo-Aga1 complex binds to 5P-RNA derived from viral mRNA as guides to

393 recognize complementary viral nucleic acid targets; then the quaternary complex activates

394 SiAga2 to induce membrane depolarization and execute cell death. The SiAgo-Aga1 complex

395 may discriminate viral nucleic acids in a similar way to RsAgo (Olovnikov et al., 2013), a long-

396 B pAgo that also uses 5P-RNA guides. As proposed for RsAgo, during the virus life cycle,

397 viral genes are highly expressed and the genome is replicated at high rates, thus generating

398 abundant mRNA and single-strand DNA that provide guides and targets for the SiAgo. 
399 Ago and CRISPR-Cas are, to date, the only two sequence-dependent nucleic acid sensing

400 defense systems. While the consequence of nucleic acid sensing is usually nucleic acid

401 degradation (Abudayyeh et al., 2016; Gasiunas et al., 2012; Jinek et al., 2012; Kazlauskiene

402 et al., 2017; Niewoehner et al., 2017; Swarts et al., 2014a; Westra et al., 2012), diverse

403 membrane proteins and other potential toxic effectors are usually found in association with

404 these systems (Ryazansky et al., 2018; Shah et al., 2019; Shmakov et al., 2018; van Beljouw

405 et al., 2021). Our work, together with a recent study on type VI-B2 CRISPR-Cas system

406 (VanderWal et al., 2021), highlights that such association represents a general yet

407 unprecedented defense strategy that leverages nucleic-acid sensing to trigger downstream

408 toxic membrane effectors to confer immunity via cell death.

409 Acknowledgments: The research was supported by National Key Research and

410 Development program of China (2019YFA0906400), National Science Foundation of China

411 (Grant No. 31970545), Fundamental Research Funds for Central Universities (Grant No.

412 2662020SKPY001) and Huazhong Agricultural University Scientific \& Technological Self-

413 innovation Foundation. R.P-R. was financed by the Lundbeck Foundation (Lundbeckfonden),

414 postdoc grant R347-2020-2346. S.A.S. is a recipient of a Novo Nordisk Foundation project

415 grant in basic bioscience [NNF18OC0052965]. C.Z. and R.W. were supported by U.S

416 National Science Foundation under IOS grant award no. 1656869. We thank the core facilities

417 of Center for Protein Research (CPR) and Experimental Teaching Center of Bioengineering at

418 Huazhong Agricultural University for technical support.

419 Author contributions: Z.Z., Y.C. and Z.H. conducted the experiments. S.A.S. and R.P-R.

420 performed bioinformatics analysis. F.Z. and C.W. predicted and analyzed the structures. C.Z.,

421 R.W. and Q.S. provided archaeal materials. R.P-R., C.Z., R.W. and Q.S. critically commented

422 the draft. W.H. acquired the funding, supervised the work and wrote the original draft. All

423 authors contributed to review and editing.

424 Competing interests: The authors declare no competing interests. 


\section{MAIN FIGURE TITLE AND LEGENDS}

Figure 1. SiAgo system defends against SMV1 by mediating Abi.

(A) Schematic of the Ago system from S. islandicus M164. The gene locus tags are indicated above the cluster. M164_1614 encodes a short Ago protein containing a MID domain and a catalytically inactive PIWI domain (PIWI*).

(B) Schematic of the inducible cassettes reconstituting the SiAgo system in the pSeSD-Ago1-2 expression plasmid.

(C) Growth curves of the $S$. islandicus strains containing the SiAgo system (Ago-1-2), or lacking it (CK), during the course of SMV1 infection at a MOI of $\sim 2\left(V_{+}\right)$in the sucrose medium. Isogenic cultures without SMV1 virus (V-) are shown as controls. The data show means of three independent replicates. Error bars indicate the standard deviations.

(D) Viral titers in the cultures post infection. The supernatant of the cultures was serially diluted and spotted onto plates carrying $S$. islandicus $\mathrm{C} 1 \mathrm{C} 2$ cells at 48 hpi.

(E) Analysis of the cell membrane polarity by $\mathrm{DiBAC}_{4}(3)$ staining. The cells were stained by $\mathrm{DiBAC}_{4}(3)$ and analyzed by flow cytometry at indicated time points post SMV1 infection. The data are shown in the green fluorescence $\left(\mathrm{DiBAC}_{4}(3)\right.$ signal, horizontal axis)-FSC (forward scattered light, vertical axis) cytograms. $\mathrm{DiBAC}_{4}(3)$-positive cells are indicated by red boxes.

443 (F) Analysis of the DNA content distributions by DAPI staining. The cells were stained by DAPI and analyzed by flow cytometry at indicated time points post viral infection. The data are shown in the blue fluorescence (DAPI signal, horizontal axis)-cell count (vertical axis) histograms. Cells exhibiting low DNA content are indicated in red boxes, while cells containing DNA content $>2$ chromosomes are indicated in blue boxes.

(G) Analysis of the cell membrane permeability by SYTO9/PI staining. The cells were stained by SYTO9 and PI simultaneously and analyzed by flow cytometry at $72 \mathrm{hpi}$. The data are shown in the green fluorescence (SYTO9 signal, horizontal axis)-red fluorescence (PI signal, vertical axis) cytograms. PI-positive cells are indicated in red boxes

452 (H) Growth curves of the infected cultures which were transferred into fresh medium at 72 453 hours post infection (hpi). Means of three independent replicates are shown. Error bars 454 indicate the standard deviations.

455 (I) Viral titers in the infected cultures at $120 \mathrm{hpi.}$

456 (J) DNA content distributions of the infected (SMV1+) and uninfected (SMV1-) cultures at 120 457 hpi. 
Figure 2. SiAgo, SiAga1 and SiAga2 are required for Abi execution and SiAga2 acts as 460 toxic effector.

461 (A) Strains containing the complete SiAgo system or incomplete versions of the system (each 462 lacking one of the three proteins), or lacking the system (CK) were grown in the presence or 463 absence of SMV1 (SMV1+ and SMV1-, respectively). DNA content distributions were 464 analyzed at $48 \mathrm{hpi}$. DNA-less cells are indicated in red boxes, while cells containing DNA 465 content $>2$ chromosomes are indicated in blue boxes.

466 (B) Viral titers of the cultures derived from the strain versions depicted in (A) at $48 \mathrm{hpi}$.

467 (C) Growth curves of the strains expressing different components of the SiAgo system in 468 sucrose (Suc) and arabinose (Ara) medium, respectively. The strains include CK and those 469 expressing Aga1, Aga2, Ago, Ago-Aga1, respectively. The data of one out of two independent 470 replicates are shown.

471 (D) Analysis of the cell membrane polarity of the cells overexpressing Aga2 or not (CK) 


\section{Figure 3. SiAga2 is a membrane protein with affinity to anionic phospholipids}

474 (A) Prediction of transmembrane topology of SiAga2 using TMHMM Server.

475 (B) Fluorescence microscopy analysis of subcellular localization of SiAga2. Images show 476 phase contrast, DAPI staining of DNA (blue), SiAga2 (green), membrane (red) and merged 477 images.

478 (C) Surface representation of the structural model of SiAga2 colored according to electrostatic 479 surface potential. The predicted basic pocket is indicated in yellow boxes. Left: side view; 480 right: bottom view.

481 (D) Binding of SiAga2 $\Delta \mathrm{C}$ to the membrane and PIP strips. The strips were incubated with $482 \mathrm{SiAga} 2 \Delta \mathrm{C}$ or not (control), and the bound SiAga2 $\Delta \mathrm{C}$ was detected by western blot. 


\section{Figure 4. The basic pocket of SiAga2 is crucial for the Abi response and binding to} 485 anionic phospholipids

486 (A) The overall view and a close-up view of the basic pocket of SiAga2. The indicated 487 residues were selected for mutagenesis. The protein is displayed in the same orientation as in 488 Figure $3 \mathrm{C}$ bottom view.

489 (B) Membrane depolarization of the cultures containing wild type (WT) or mutated SiAgo 490 systems at 0 and $9 \mathrm{~h}$ post SMV1 infection. The mutations are within SiAga2: R7A-R8A (M1), 491 K12A-K13A (M2) and R7A-R8A-K12A-K13A (M3). CK denotes the control lacking the SiAgo 492 system.

493 (C) DNA content distributions of the cultures containing WT or mutated SiAgo systems at $48 \mathrm{~h}$ 494 post SMV1 infection.

495 (D) Viral titers of the cultures containing WT or mutated SiAgo systems at $48 \mathrm{~h}$ post SMV1 496 infection.

497 (E) Binding of SiAga2 $\Delta C$ (WT) and its mutants to the membrane strip. 


\section{Figure 5. Interplay between SiAgo, SiAga1 and SiAga2}

500 (A) Growth curves of the strains lacking the SiAgo system (CK), expressing Aga2, Ago-Aga1

501 or all the three proteins (Ago-1-2) in Ara medium. The data of one of three independent

502 replicates are shown.

503 (B) Quantification of the membrane-depolarized cells in the strains. Data shown are means of

504 three independent repeats \pm standard deviation. ${ }^{*}: p<0.05 ;{ }^{* *}: p<0.01$.

505 (C) Gel filtration analysis of purified His-MBPAga2, His-Aga1 and His-Ago, respectively.

506 (D) Gel filtration analysis of co-expressed MBPAga2+His-Aga1, MBPAga2+His-Ago, and

507 Aga1+His-Ago, respectively.

508 (E) Gel filtration analysis of co-expressed MBPAga2+Aga1+His-Ago and MBP+Aga1+His-Ago, 509 respectively.

510 (F) Gel filtration analysis of co-expressed Aga2+Aga1+His-Ago and Aga1+His-Ago from

511 Sulfolobus cells, respectively.

512 (G) A model depicting the interactions between the three proteins in Sulfolobus cells. 


\section{Figure 6. Nucleic acid binding and recognition by SiAgo and SiAga1 complex}

515 (A) Nucleic acid binding of SiAgo-Aga1 complex. The different substrates are indicated below 516 the panels. The concentrations of SiAgo-Aga1 complex were 0, 150, 300, 450, $600 \mathrm{nM}$, 517 respectively.

518 (B) Quantification of the free substrates from (A). The data show means of three independent 519 replicates. Error bars indicate the standard deviations.

520 (C) Nucleic acid recognition of SiAgo-Aga1 complex preloading with 5P-RNA. SiAgo-Aga1

521 complex $(400 \mathrm{nM})$ was incubated with $100 \mathrm{nM} 5 \mathrm{P}-\mathrm{RNA}$. Then, the mixture was serially diluted 522 and further incubated with $50 \mathrm{nM}$ FAM-labeled target DNA (TDNA) and non-target DNA

523 (NTDNA) (left panel), or target RNA (TRNA) and non-target RNA (NTRNA) (right panel).

524 Unlabeled target and non-target nucleic acids were also supplemented up to $1 \mu \mathrm{M}$ as

525 competitors, as indicated. 


\section{Figure 7. Functional characterization of the conserved MID domain motif}

528 (A) Target DNA binding of the wild type (WT) and mutated Ago-Aga1-gRNA ternary

529 complexes. The ternary complexes were generated by incubating WT and mutated SiAgo-

530 Aga1 complexes (400 nM) with $100 \mathrm{nM}$ 5P-RNA. Then, target DNA was incubated with a

531 gradient of the ternary complexes. WT: wild type; M1: Ago-K142A; M2: Ago-K183A. Non-

532 labeled competitors were supplemented at $1 \mu \mathrm{M}$ as indicated. "duplex" represents the duplex

533 of 5P-RNA and target DNA. Red arrow indicates a band only observed in gel of the mutated

534 complexes.

535 (B) Release of guide RNA from WT and mutated SiAgo-Aga1 complexes. FAM-labeled guide

536 RNA was bound by WT and mutated SiAgo-Aga1 complexes at first. Then, the ternary

537 complex was incubated with water, target DNA (+: $100 \mathrm{nM} ;++: 200 \mathrm{nM})$, non-target DNA (1

$538 \mu \mathrm{M}$ ) or both. Free guide RNA and RNA/DNA duplex were also loaded onto the gels as

539 markers.

540 (C) Quantification of the unbound RNA from (B). Data shown are means of three independent 541 repeats \pm standard deviation. *: $\mathrm{P}<0.05$.

542 (D) Membrane depolarization of the cultures expressing WT or mutated SiAgo systems at 0 543 and $9 \mathrm{~h}$ post SMV1 infection.

544 (E) DNA content distributions of the cultures expressing WT or mutated SiAgo systems at 0 545 and $48 \mathrm{~h}$ post SMV1 infection.

546 (F) Viral titers of the cultures expressing WT or mutated SiAgo systems at $48 \mathrm{hpi}$. 


\section{Figure 8. Model for the antiviral immune response of SiAgo system}

549 Prior to viral infection, apo SiAgo-Aga1 complex resides in the cytoplasm or is recruited to

550 SiAga2 on the membrane without triggering it. During viral infection, high transcription of viral

551 genes and fast replication of the viral genome provide abundant RNA and DNA substrates for

552 the SiAgo-Aga1 complex to obtain guides, and also for the guide-loaded complex to search

553 targets. Target binding leads to the activation of SiAga2, probably through direct interaction,

554 which then induces the death of infected cells through membrane depolarization.

555 


\section{STAR METHODS}

\section{RESOURCE AVAILABILITY}

558 Lead Contact

559 Further information and requests for resources and reagents should be directed to and will be

560 fulfilled by the Lead Contact, Wenyuan Han (hanwenyuan@mail.hzau.edu.cn).

\section{Materials Availability}

562 Plasmids, strains and other unique reagents generated in this study are available upon

563 request.

\section{Data and Code Availability}

565 This study did not generate any unique datasets or code.

\section{EXPERIMENTAL MODELS AND SUBJECT DETAILS}

567 S. islandicus E233S1 (Deng et al., 2009) was used as the genetic host to express the SiAgo system. The strain was grown at $78{ }^{\circ} \mathrm{C}$ in SCVU medium as indicated previously (basic salts medium supplemented with $0.2 \%(\mathrm{w} / \mathrm{v})$ sucrose, $0.2 \%(\mathrm{w} / \mathrm{v})$ casamino acids, $0.2 \%(\mathrm{w} / \mathrm{v})$ uracil and a vitamin mixture) (Zhao et al., 2021). The strains carrying a pSeSD-derived expression plasmid were grown in SCV medium lacking uracil. STV medium in which casamino acids were replaced with tryptone was used for large scale cultivation. Arabinose was supplemented at $0.2 \%(\mathrm{w} / \mathrm{v})$ to induce expression of the proteins of interest. SMV1 (Sulfolobus Monocaudavirus 1) (Uldahl et al., 2016) was used to analyze the immune functions of the SiAgo system and its variants. S. islandicus C1C2 (Gudbergsdottir et al., 2011) was used for virus propagation and plaque forming unit (PFU) assay. Escherichia coli DH5a and BL21 (DE3) were routinely grown in LB medium and used for plasmid cloning and protein expression, respectively.

\section{METHOD DETAILS}

\section{Construction of $E$. coli expression plasmids and strains}

581 To express the proteins in E. coli, the coding sequences of SiAgo and SiAga1 were amplified

582 from the genomic DNA of $S$. islandicus M164 by PCR using the primers listed in Table S4.

583 The gene fragments were inserted in $\mathrm{pET} 30 \mathrm{aN}$ between the Nhel and Notl restriction sites,

584 such that the encoded proteins have an $\mathrm{N}$-terminal $6 \times$ His tag. The $\mathrm{pET} 30 \mathrm{aN}$ vector was

585 constructed by inserting an Nhel site into pET30a to increase the compatibility of the 586 restriction sites between pSeSD and pET30a. Since the coding sequence of SiAga2 that was amplified from the genomic DNA resulted in poor protein expression in E. coli, we ordered a

588 synthetic, codon-optimized sequence of SiAga2 from Tingke (Beijing, China) (Table S3). To

589 facilitate protein expression and stability, the synthesized gene was fused with the coding 590 sequence of the maltose-binding protein (MBP). First, the optimized coding sequence of 591 SiAga2 was inserted into PMAL-c5x between the Ndel and Notl sites; then, the fused gene 592 fragment of MBP-Aga2 was amplified by PCR and inserted into PCDFDuet-1 between BamHI 593 and Notl, yielding pCDFDuet-1-Aga2 encoding the His-MBPAga2 fusion protein. To express 594 SiAga2 $\triangle C$, a truncated version that lacks the transmembrane region, the coding sequence 595 was amplified from the pCDFDuet-1-Aga2 plasmid and inserted into $\mathrm{pET} 30 \mathrm{aN}$ between the 596 Nhel and Xhol sites. The resulting plasmid constructs, i.e. pET30aN-Ago, pET30aN-Aga1, 
pCDFDuet-1-Aga2 and pET30aN-Aga2 $\Delta C$, were transformed into E. coli BL21(DE3) to generate strains for protein expression.

To perform the co-expression assay, we firstly constructed the plasmids expressing the Histag free (HF) SiAga1 and SiAga2. The aga1 gene was inserted into pET21d between Nde1 and Xho1, while the fused gene of mbpaga2 was inserted in pCDFDuet-1 between Ndel and Xhol, generating pET21d-Aga1(HF) and pCDFDuet-1-Aga2(HF), respectively. pCDFDuet-1$\mathrm{MBP}(\mathrm{HF})$, which encodes His-tag free MBP, was also constructed in a similar way. To obtain the co-expression strains, either two or three plasmids were simultaneously transformed into E. coli BL21(DE3). The obtained co-expression strains include those carrying pET30aN-Ago + pET21d-Aga1(HF), pET30aN-Ago + pCDFDuet-1-Aga2(HF), pET30aN-Aga1 + pCDFDuet1-Aga2(HF), pET30aN-Ago + pET21d-Aga1(HF) + pCDFDuet-1-Aga2(HF), pET30aN-Ago + pET21d-Aga1(HF) + pCDFDuet-1-MBP(HF).

To express the mutated SiAgo and SiAga2 $\Delta \mathrm{C}$, overlapping PCR was performed to generate site mutations within the coding sequences, and the mutated genes were inserted in pET30aN as indicated above. The plasmids encoding mutated SiAgo were also cotransformed with $\mathrm{pET} 21 \mathrm{~d}-\mathrm{Aga1}(\mathrm{HF})$ to express mutated SiAgo-Aga1 complexes. All the primers were synthesized by Tingke (Beijing, China). All the plasmids were confirmed by sequencing before transformation. The plasmids are listed in Table S1.

\section{Construction of Sulfolobus expression plasmids and strains}

616 The pSeSD shuttle vector (Peng et al., 2012) was used to construct the plasmids expressing Ago and its associated proteins in S. islandicus E233S1 (Table S1). To construct them, the coding sequences of SiAgo, SiAga1, SiAga2, and SiAga1+Aga2 were amplified from the genomic DNA of $S$. islandicus M164. The coding sequences of SiAga1, SiAga2, and SiAga1+Aga2 were inserted between Ndel and Notl in pSeSD, yielding pSeSD-Aga1, pSeSD-Aga2 and pSeSD-Aga1-Aga2, while the ago gene was inserted between Nhel and Notl, resulting in pSeSD-Ago. To co-express SiAgo and its associated proteins, the expression cassette of SiAgo from the pSeSD-Ago plasmid was amplified using the primers Aras-F_Smal and Ago-R_Notl with the plasmid as template and inserted in pSeSD-Aga1, pSeSD-Aga2 and pSeSD-Aga1-Aga2 between Notl and Smal respectively, generating pSeSD-Ago-Aga1, pSeSD-Ago-Aga2 and pSeSD-Ago-1-2. When co-expressed, only SiAgo carries an $\mathrm{N}$-terminal $\mathrm{His}$ tag. The plasmids expressing mutated SiAgo and SiAga2 were constructed in a similar way, except that the wild type coding sequences were replaced by those carrying the indicated mutations. Then, the plasmids were transformed into $S$. islandicus E233S1 to generate the corresponding expression strains (Table S2). The detailed procedures of $S$. islandicus E233S1 cultivation and transformation were described previously (Zhao et al., 2021). All the primers were synthesized by Tingke (Beijing, China). All the plasmids were confirmed by sequencing before transformation.

\section{Protein expression and purification}

635 To express the proteins from E. coli BL21(DE3), the strains carrying the indicated plasmids 636 were grown in LB medium containing the corresponding antibiotics. At an optical density of $637 \sim 1.0$, protein expression was induced with $0.5 \mathrm{mM} \mathrm{IPTG}$ at $18{ }^{\circ} \mathrm{C}$ for $18 \mathrm{~h}$. To express the 638 proteins from $S$. islandicus E233S1, the strain carrying corresponding plasmids was grown to 639 an optical density of $\sim 0.6$ in STV medium and then protein expression was induced by $0.2 \%$ $640(\mathrm{w} / \mathrm{v})$ arabinose for $24 \mathrm{~h}$. Then, the cells were collected by centrifugation at $7000 \mathrm{~g}$ for $10 \mathrm{~min}$. 
641 The cell mass was resuspended in $50 \mathrm{ml}$ of lysis buffer (20 mM HEPES pH 7.5, $20 \mathrm{mM}$

642 imidazole, $500 \mathrm{mM} \mathrm{NaCl}$ ) and stored at $-80^{\circ} \mathrm{C}$ until protein purification.

The purification procedure for all the protein and protein complexes was similar. The common steps include cell extract preparation, Ni-NTA affinity chromatography (NAC), anion exchange chromatography (AEC) and size exclusion chromatography (SEC). When full length SiAga2 was purified, $1 \% \mathrm{n}$-Dodecyl- $\beta$-D-Maltopyranoside (DDM) (RHAWN, Shanghai, China) was used to treat the cell extract at $4{ }^{\circ} \mathrm{C}$ for $12 \mathrm{~h}$ and the buffers used for NAC, AEC and SEC contained $0.02 \%$ DDM.

To prepare cell extracts, the cells were disrupted by French press and the lysate was subjected to centrifugation at $13000 \mathrm{~g}$ for $40 \mathrm{~min}$ to remove cell debris. Before centrifugation, the cell lysate was treated with $1 \%$ DDM if full length SiAga2 was purified. Then, the cell extract was loaded onto Ni-NTA agarose resin columns (Cytiva, Marlborough, MA, USA). After the column was washed with lysis buffer containing $60 \mathrm{mM}$ imidazole, His-tagged proteins were eluted using a lysis buffer containing $300 \mathrm{mM}$ imidazole. Then, the elution fractions were concentrated employing an ultra-centrifugal filter (Eppendorf, Hamburg, Germany) and then diluted for 30 -fold with Buffer A ( $25 \mathrm{mM}$ Tris- $\mathrm{HCl}, \mathrm{pH}$ 8.0). The diluted samples were loaded onto a $5 \mathrm{~mL}$ Q FF column (Cytiva, Marlborough, MA, USA) and the proteins were eluted using a $35 \mathrm{~mL}$ linear gradient of $0-1 \mathrm{M} \mathrm{NaCl}$. The fractions containing target proteins were concentrated again and loaded onto a Superdex 200 column (Cytiva, Marlborough, MA, USA). Finally, the proteins were eluted with BufferC $(20 \mathrm{mM}$ Tris $-\mathrm{HCl} \mathrm{pH}$ 7.5, $250 \mathrm{mM} \mathrm{NaCl}$ ) and analyzed by SDS-PAGE.

\section{Flow cytometry}

The cellular DNA content, membrane polarity and membrane permeability were analyzed with flow cytometry. The cell samples were prepared following procedures previously established in our group with some modifications (Han et al., 2017). Specifically, the cells for cellular DNA content analysis were fixed with $70 \%$ ethanol at $4{ }^{\circ} \mathrm{C}$ for at least $12 \mathrm{~h}$, and then washed with 1 $\mathrm{mL}$ of washing buffer (10 mM Tris- $\mathrm{HCl}, \mathrm{pH} 7.5,10 \mathrm{mM} \mathrm{MgCl}$ ). The cells were collected again and resuspended in $30 \mu \mathrm{L}$ washing buffer. DAPI (Thermo Scientific, Waltham, MA, USA) was added into the cell suspension to a final concentration of $3.3 \mu \mathrm{g} / \mathrm{mL}$ and the cells were stained for $30 \mathrm{~min}$ on ice in darkness. Then, the cell suspensions were diluted in $1 \mathrm{~mL}$ and loaded onto a cytoflex-LX flow cytometer (Beckman Coulter, Brea, CA, USA) with a $375 \mathrm{~nm}$ laser. A dataset of at least 40,000 cells was recorded for each sample, including fluorescence signal at $450 \mathrm{~nm}, \mathrm{FSC}$ (forward scattered light), and SSC (side scattered light). At last, the data were analyzed and visualized by FlowJo v.10 (BD Biosciences, Franklin Lakes, NJ, USA).

The cells for the analyses of membrane polarity and membrane permeability were collected from $0.1 \mathrm{~mL}$ culture, washed with fresh medium, and resuspended in $50 \mu \mathrm{L}$ fresh medium. Then, $0.5 \mu \mathrm{L}$ of dye mix containing SYTO 9 and propidium iodide $(\mathrm{PI})$ in the ratio 1:1 (LIVE/DEAD BacLight bacterial viability kit) (Thermo Scientific, Waltham, MA, USA) was supplemented to stain the cells for membrane permeability analysis, while $\mathrm{DiBAC}_{4}$ (3) (SigmaAldrich, St. Louis, MO, USA) was added up to the concentration of $0.5 \mu \mathrm{g} / \mathrm{ml}$ for membrane polarity analysis. The cells were stained in darkness for $15 \mathrm{~min}$ at room temperature and analyzed by Cytoflex-LX flow cytometer with a $488 \mathrm{~nm}$ laser. For the SYTO9/PI-stained cells, fluorescence signal at $525 \mathrm{~nm}$ (green, SYTO9) and $610 \mathrm{~nm}$ (red, PI) was analysed, while the 
green signal was measured after DiBAC straining. The data were also analyzed and visualized by FlowJo v.10.

\section{Virus propagation}

A sensitive strain, S. islandicus C1C2 (Gudbergsdottir et al., 2011), was grown at exponential phase for at least $72 \mathrm{~h}$. At an optical density at $600 \mathrm{~nm}\left(\mathrm{OD}_{600}\right)$ of $\sim 0.2,100 \mathrm{~mL}$ of the culture was infected with SMV1 at a MOI of $<0.1$. At $48 \mathrm{~h}$ post infection (hpi), the cells were removed by centrifugation at $8000 \mathrm{~g}$ for $10 \mathrm{~min}$ and the virus particles in the supernatant were concentrated by ultrafiltration using 1,000,000-molecular-weight-cutoff (MWCO) centrifugal filter units (Sigma-Aldrich, St. Louis, MO, USA). The concentrated virus particles were then dissolved in viral storage buffer containing $20 \mathrm{mM}$ Tris- $\mathrm{HCl}, \mathrm{pH}=7.0,20 \%$ glycerol and stored

694 at $4{ }^{\circ} \mathrm{C}$ before use.

\section{Plaque forming unit assay}

696 SCVU plates were prepared before the assay (Zhao et al., 2021). To determine viral titer in the storage buffer, the storage buffer was serially diluted and mixed with $4 \mathrm{~mL}$ fresh $S$. islandicus $\mathrm{C} 1 \mathrm{C} 2$ culture $\left(\mathrm{OD}_{600}\right.$ around 0.2$)$. The mixture was preheated at $75^{\circ} \mathrm{C}$ and further mixed with an equal volume of preheated $0.4 \%$ Gelzan CM (Duchefa-biochemie, Haarlem, Netherlands). Then, the mixture was spread onto pre-warmed SCVU plates. Plaques were counted after the plates had been incubated at $75^{\circ} \mathrm{C}$ for two days.

To perform the drop plaque assay, $\mathrm{C} 1 \mathrm{C} 2$ plates were firstly prepared by spreading the mixture of $4 \mathrm{~mL}$ preheated $S$. islandicus $\mathrm{C} 1 \mathrm{C} 2$ culture $\left(\mathrm{OD}_{600}\right.$ around 0.2$)$ and $4 \mathrm{~mL}$ preheated $0.4 \%$ Gelzan CM onto SCVU plates. Then, cells were removed from the SMV1-infected cultures and the supernatant was serially diluted. Ten $\mu \mathrm{L}$ of the diluted supernatant (from $10^{-1}$ to $10^{-6}$ ) was dropped on the $\mathrm{C} 1 \mathrm{C} 2$ plates. Pictures of the plates were taken after incubation at $75^{\circ} \mathrm{C}$ for two days.

\section{Viral infection and sampling}

709 The strains were grown at exponential phase for at least $72 \mathrm{~h}$. At an optical density of $\sim 0.1$,

$71050 \mathrm{~mL}$ of the cultures were infected with SMV1 at a MOI of $\sim 2$. The MOI was calculated 711 based on the estimation that $1 \mathrm{~mL}$ of $\mathrm{OD}_{600}=0.1$ culture contains $1 \times 10^{8}$ cells. At indicated time 712 points, samples were removed from the cultures for analysis. When applicable, the cultured 713 cells were collected and diluted to an optical density of $\sim 0.1$ in fresh medium at 72 hpi.

\section{Membrane and PIP strip screening assay}

Membrane and PIP strips (Echelon Biosciences, Salt Lake City, UT, USA) were firstly blocked overnight at $4{ }^{\circ} \mathrm{C}$ in a blocking buffer $(20 \mathrm{mM}$ Tris- $\mathrm{HCl} \mathrm{pH} \mathrm{8.0,100} \mathrm{mM} \mathrm{NaCl}, 0.1 \%$ Tween 40 , $3 \% \mathrm{BSA})$, then incubated with a mixture of SiAga2 $\Delta \mathrm{C}(100 \mathrm{ng} / \mathrm{mL})$ and anti-SiAga2 serum ( $1: 10000$ dilution) in the blocking buffer for $2 \mathrm{~h}$ at room temperature. Then, the membrane was washed 3 times with washing buffer $(20 \mathrm{mM}$ Tris- $\mathrm{HCl} \mathrm{pH} \mathrm{8.0,100} \mathrm{mM} \mathrm{NaCl,} 0.1 \%$ Tween 40) for $10 \mathrm{~min}$. Next, the membrane was incubated with blocking buffer containing HRPconjugated secondary antibody (1:40000 dilution) (Goat Anti-Rabbit IgG) (Abbkine, Wuhan, China) for $30 \mathrm{~min}$ at room temperature, followed by another 3 times' washing step with washing buffer (20mM Tris- $\mathrm{HCl} \mathrm{pH} \mathrm{8.0,100} \mathrm{mM} \mathrm{NaCl,} \mathrm{0.1 \%} \mathrm{Tween} \mathrm{40)} \mathrm{for} 10 \mathrm{~min}$. Finally, the signal was detected by the Clarity Western ECL Substrate (Bio-Rad, Hercules, CA, USA) and the membrane was scanned with Tanon 5200 (Tanon, Shanghai, China). The affinity of

726 SiAga2 $\Delta C$ mutants was analyzed in the same procedure. 


\section{Electrophoretic mobility shift assay (EMSA)}

728 To analyze the nucleic acid affinity of different proteins, four different 3'-FAM labeled nucleic acid substrates (5P-DNA, 5OH-DNA, 5P-RNA and 5OH-RNA) were incubated with SiAgo,

730 SiAga1 and SiAgo-Aga1 complex, respectively, in a $10-\mu \mathrm{L}$ mixture at $70{ }^{\circ} \mathrm{C}$ for $20 \mathrm{~min}$. The incubation buffer, i.e. EMSA buffer, contained $20 \mathrm{mM}$ Mes pH 6.0 and $5 \mathrm{mM} \mathrm{MnCl}_{2}$. The sequences of the substrates are listed in Table S3. The concentration of the substrates was fixed as $100 \mathrm{nM}$, while the concentrations of proteins varied as indicated in the figure legends. The concentration of SiAgo-Aga1 complex was calculated based on the estimation that the stoichiometry of SiAgo and SiAga1 is 1:1 in the complex. After incubation, the reaction samples were mixed with $4 \mu \mathrm{L}$ loading dye containing $60 \%$ glycerol, $0.1 \%$ bromophenol blue and $0.1 \%$ xylene cyanol, and loaded onto $8 \%$ native polyacrylamide gels. The electrophoresis was performed in $0.5 \times$ TB buffer ( $44.5 \mathrm{mM}$ Tris, $44.5 \mathrm{mM}$ boric acid) at $100 \mathrm{~V}$ for $1 \mathrm{~h}$. At last, the fluorescent signal was visualized using a Fujifilm FLA-5100 scanner (Fujifilm Life Science,

740 Japan).

741 To analyze the target binding ability of the SiAgo-Aga1-gRNA ribonucleoprotein (RNP)

742 complex, $400 \mathrm{nM}$ SiAgo-Aga1 complex was incubated with $100 \mathrm{nM}$ unlabeled 5P-RNA in the

743 EMSA buffer at $70^{\circ} \mathrm{C}$ for 20 min. Aliquots of the mixture were diluted 2 and 4 times, respectively. Then, $50 \mathrm{nM}$ of FAM-labeled target and non-target DNA or RNA substrates (TDNA, NTDNA, TRNA and NTRNA) were supplemented into the mixture and further incubated at $70{ }^{\circ} \mathrm{C}$ for $20 \mathrm{~min}$. Competitive substrates were also supplemented in aliquots up to a final concentration of $1 \mu \mathrm{M}$. At last, the samples were analyzed by native gel electrophoresis and visualized with a Fujifilm scanner. The guide binding and target binding abilities of the mutated SiAgo-Aga1 complexes were analyzed in the same way as the wild 750 type complex.

751 To analyze the stability of the SiAgo-Aga1-gRNA RNP, $400 \mathrm{nM}$ SiAgo-Aga1 complex was 752 incubated with $100 \mathrm{nM}$ FAM-labeled 5P-RNA in the EMSA buffer at $70{ }^{\circ} \mathrm{C}$ for $20 \mathrm{~min}$. Then, aliquots of the mixture were further incubated with water as control, unlabeled target DNA $(100 \mathrm{nM}$ and $200 \mathrm{nM})$, non-target DNA $(1 \mu \mathrm{M})$, or both, at $70{ }^{\circ} \mathrm{C}$ for $20 \mathrm{~min}$. The samples were then analyzed by native gel electrophoresis and visualized with a Fujifilm scanner. The mutated SiAgo-Aga1 complexes were analyzed in the same way as the wild type complex.

\section{Immunofluorescence microscopy}

758 To analyze the subcellular localization of SiAga2, the strain expressing SiAga2 was

759 transferred into Ara medium. After $24 \mathrm{~h}$, cells from $3 \mathrm{~mL}$ cultures were collected by

760 centrifugation at $3000 \mathrm{~g}$ for $10 \mathrm{~min}$, washed with PBST buffer (137 mM NaCl, $2.7 \mathrm{mM} \mathrm{KCl}, 10$

$761 \mathrm{mM} \mathrm{Na}_{2} \mathrm{HPO}_{4}, 2 \mathrm{mM} \mathrm{KH}_{2} \mathrm{PO}_{4}, 0.05 \%$ Tween 40, pH7.6), and resuspended in $300 \mu \mathrm{L} \mathrm{PBST}$

762 buffer. Cold ethanol was added into the cell solution up to a final concentration of $70 \%(\mathrm{v} / \mathrm{v})$ to

763 fix the cells for at least $12 \mathrm{~h}$. Then, the cells were collected again, washed with PBST buffer

764 twice, and blocked in PBST buffer containing $2 \%$ BSA for $2 \mathrm{~h}$ at room temperature. Next, the

765 cells were incubated with anti-SiAga2 serum (1:1000 dilution) in the PBST buffer containing 2\%

766 BSA at $4{ }^{\circ} \mathrm{C}$ overnight. This was followed by an incubation with secondary antibody Dylight

767488 Affinipure Goat anti-Rabbit $\lg G(H+L)(1: 1000$ dilution)( Abbkine, Wuhan, China) in the

768 PBST buffer containing $2 \%$ BSA at room temperature for $2 \mathrm{~h}$. Before and after each

769 incubation, the cells were washed with PBST buffer for three times. After the last washing, the

770 cells were resuspended in $30 \mu \mathrm{L}$ PBST containing $3.3 \mu \mathrm{g} / \mathrm{mL}$ DAPI and $10 \mathrm{ng} / \mu \mathrm{L}$ membrane 
771 staining dye FM4-64X (Thermo Scientific, Waltham, MA, USA), and incubated for 10 min on

772 ice in darkness. At last, $3 \mu \mathrm{L}$ of the cell solution was dropped onto a slide and photos were

773 captured with a Nikon A1 HD25 camera (Nikon, Japan).

\section{Western blot}

775 Proteins from SDS-PAGE gels were transferred onto a PVDF membrane (Bio-Rad, Hercules, 776 CA, USA) using Trans-Blot SD Semi-Dry Transfer Cell (Bio-Rad, Hercules, CA, USA). The 777 membrane was blocked in TBST buffer (50 mM Tris, $100 \mathrm{mM} \mathrm{Nacl}, 0.05 \%$ Tween 40, pH 8.0)

778 containing $6 \%$ milk, followed by incubation with anti-SiAga2 serum or anti-SiAgo serum, as

779 indicated. Upon completion of three consecutive washing steps, the membrane was

780 incubated with the secondary antibody (Goat Anti-Rabbit IgG) (Abbkine, Wuhan, China). After

781 removing unspecific binding, the Clarity Western ECL Substrate (Bio-Rad, Hercules, CA, USA)

782 was dropped onto the membrane and the signals were recorded using Tanon 5200 (Tanon,

783 Shanghai, China).

\section{Bioinformatics analysis}

785 Genetic neighborhood analysis and visualization was performed employing the EFI server

786 (Gerlt, 2017). The dotplot between S. islandicus strains M164 and M1425 were drawn using

787 the "nucmer" command from the MUMmer 4 software package

788 (https://github.com/mummer4/mummer). Sequence alignment was carried out using Clustal W, 789 and the results were visualized with Jalview (Waterhouse et al., 2009). HHpred (Soding et al., 790 2005) was used to identify putative functional domains in M164_1612, M164_1613 and 791 M164_1615. The structure of SiAga2 was predicted by AlpfaFold2 following the published 792 procedures (Jumper et al., 2021). The structural model that shows the highest predicted IDDT 793 (Local Distance Difference Test) was selected for further analysis.

\section{QUANTIFICATION AND STATISTICAL ANALYSIS}

\section{Growth curves}

796 The optical density at $600 \mathrm{~nm}$ was measured for each culture and the values were plotted to 797 time (in hours). The data are either displayed as means of three independent replicates, with 798 error bars representing standard deviations (Figure 1), or shown in each replicate (Figure 2, $799 \quad$ Figure 5 and Figure S2)

\section{$800 \quad$ Flow cytometry}

801 Membrane-depolarized cells, i.e. $\mathrm{DiBAC}_{4}(3)$-positive cells, are quantified by FlowJo v.10. The 802 data show means of three independent replicates, with error bars representing standard 803 deviations (Figure 5).

\section{EMSA}

805 Quantification of labeled substrate in the gels was performed with ImageJ. Error bars show 806 standard deviations of three independent experiments (Figure 6 and Figure 7).

807 The unpaired t-test was used to calculate the P-value: $<0.05={ }^{*} ;<0.01={ }^{* *}$. 
810 Abudayyeh, O.O., Gootenberg, J.S., Konermann, S., Joung, J., Slaymaker, I.M., Cox, D.B., 811 Shmakov, S., Makarova, K.S., Semenova, E., Minakhin, L., et al. (2016). C2c2 is a singlecomponent programmable RNA-guided RNA-targeting CRISPR effector. Science 353,

813 aaf5573.

814 Bautista, M.A., Zhang, C., and Whitaker, R.J. (2015). Virus-induced dormancy in the archaeon Sulfolobus islandicus. mBio 6.

816 Cho, W., and Stahelin, R.V. (2005). Membrane-protein interactions in cell signaling and membrane trafficking. Annual review of biophysics and biomolecular structure 34, 119-151.

818 Deng, L., Zhu, H., Chen, Z., Liang, Y.X., and She, Q. (2009). Unmarked gene deletion and host-vector system for the hyperthermophilic crenarchaeon Sulfolobus islandicus.

820 Extremophiles : life under extreme conditions 13, 735-746.

821 Ding, J., Wang, K., Liu, W., She, Y., Sun, Q., Shi, J., Sun, H., Wang, D.C., and Shao, F.

822 (2016). Pore-forming activity and structural autoinhibition of the gasdermin family. Nature 535,

$823 \quad 111-116$.

824 Dondelinger, Y., Declercq, W., Montessuit, S., Roelandt, R., Goncalves, A., Bruggeman, I., 825 Hulpiau, P., Weber, K., Sehon, C.A., Marquis, R.W., et al. (2014). MLKL compromises plasma 826 membrane integrity by binding to phosphatidylinositol phosphates. Cell reports 7, 971-981.

827 Doron, S., Melamed, S., Ofir, G., Leavitt, A., Lopatina, A., Keren, M., Amitai, G., and Sorek, R. 828 (2018). Systematic discovery of antiphage defense systems in the microbial pangenome.

829 Science 359.

830 Duncan-Lowey, B., McNamara-Bordewick, N.K., Tal, N., Sorek, R., and Kranzusch, P.J. 831 (2021). Effector-mediated membrane disruption controls cell death in CBASS antiphage 832 defense. Molecular cell.

833 Durmaz, E., and Klaenhammer, T.R. (2007). Abortive phage resistance mechanism AbiZ 834 speeds the lysis clock to cause premature lysis of phage-infected Lactococcus lactis. Journal 835 of bacteriology $189,1417-1425$.

836 Gasiunas, G., Barrangou, R., Horvath, P., and Siksnys, V. (2012). Cas9-crRNA

837 ribonucleoprotein complex mediates specific DNA cleavage for adaptive immunity in bacteria.

838 Proceedings of the National Academy of Sciences of the United States of America 109, 839 E2579-2586.

840 Gerlt, J.A. (2017). Genomic Enzymology: Web Tools for Leveraging Protein Family 841 Sequence-Function Space and Genome Context to Discover Novel Functions. Biochemistry $84256,4293-4308$.

843 Gudbergsdottir, S., Deng, L., Chen, Z., Jensen, J.V., Jensen, L.R., She, Q., and Garrett, R.A. 844 (2011). Dynamic properties of the Sulfolobus CRISPR/Cas and CRISPR/Cmr systems when 845 challenged with vector-borne viral and plasmid genes and protospacers. Molecular 846 microbiology 79, 35-49.

847 Guo, T., Han, W., and She, Q. (2019). Tolerance of Sulfolobus SMV1 virus to the immunity of 848 I-A and III-B CRISPR-Cas systems in Sulfolobus islandicus. RNA biology 16, 549-556.

849 Han, W., Xu, Y., Feng, X., Liang, Y.X., Huang, L., Shen, Y., and She, Q. (2017). NQO850 Induced DNA-Less Cell Formation Is Associated with Chromatin Protein Degradation and 851 Dependent on A0A1-ATPase in Sulfolobus. Frontiers in microbiology 8, 1480. 
He, R., Wang, L., Wang, F., Li, W., Liu, Y., Li, A., Wang, Y., Mao, W., Zhai, C., and Ma, L. (2019). Pyrococcus furiosus Argonaute-mediated nucleic acid detection. Chemical communications 55, 13219-13222.

Hegge, J.W., Swarts, D.C., and van der Oost, J. (2018). Prokaryotic Argonaute proteins: novel genome-editing tools? Nature reviews Microbiology 16, 5-11.

Hutvagner, G., and Simard, M.J. (2008). Argonaute proteins: key players in RNA silencing. Nature reviews Molecular cell biology 9, 22-32.

Isaev, A.B., Musharova, O.S., and Severinov, K.V. (2021). Microbial Arsenal of Antiviral Defenses. Part II. Biochemistry Biokhimiia 86, 449-470.

Jensen, S.M., Brandl, M., Treusch, A.H., and Ejsing, C.S. (2015). Structural characterization of ether lipids from the archaeon Sulfolobus islandicus by high-resolution shotgun lipidomics. Journal of mass spectrometry : JMS 50, 476-487.

Jinek, M., Chylinski, K., Fonfara, I., Hauer, M., Doudna, J.A., and Charpentier, E. (2012). A programmable dual-RNA-guided DNA endonuclease in adaptive bacterial immunity. Science 337, 816-821.

Johnson, A., Wein, T., Mayer, M., Duncan-Lowey, B., Yirmiya, E., Oppenheimer-Shaanan, Y., Amitai, G., Sorek, R., and Kranzusch, P. (2021). Bacterial gasdermins reveal an ancient mechanism of cell death. bioRxiv.

Jolly, S.M., Gainetdinov, I., Jouravleva, K., Zhang, H., Strittmatter, L., Bailey, S.M., Hendricks, G.M., Dhabaria, A., Ueberheide, B., and Zamore, P.D. (2020). Thermus thermophilus Argonaute Functions in the Completion of DNA Replication. Cell 182, 1545-1559 e1518. Jumper, J., Evans, R., Pritzel, A., Green, T., Figurnov, M., Ronneberger, O., Tunyasuvunakool, K., Bates, R., Zidek, A., Potapenko, A., et al. (2021). Highly accurate protein structure prediction with AlphaFold. Nature 596, 583-589.

Kaya, E., Doxzen, K.W., Knoll, K.R., Wilson, R.C., Strutt, S.C., Kranzusch, P.J., and Doudna, J.A. (2016). A bacterial Argonaute with noncanonical guide RNA specificity. Proceedings of the National Academy of Sciences of the United States of America 113, 4057-4062.

Kazlauskiene, M., Kostiuk, G., Venclovas, C., Tamulaitis, G., and Siksnys, V. (2017). A cyclic oligonucleotide signaling pathway in type III CRISPR-Cas systems. Science 357, 605-609.

Ketting, R.F. (2011). The many faces of RNAi. Developmental cell 20, 148-161.

Koga, Y., and Morii, H. (2005). Recent advances in structural research on ether lipids from archaea including comparative and physiological aspects. Bioscience, biotechnology, and biochemistry 69, 2019-2034.

Krogh, A., Larsson, B., von Heijne, G., and Sonnhammer, E.L. (2001). Predicting transmembrane protein topology with a hidden Markov model: application to complete genomes. Journal of molecular biology 305, 567-580.

Kropocheva, E., Kuzmenko, A., Aravin, A.A., Esyunina, D., and Kulbachinskiy, A. (2021). A programmable pAgo nuclease with universal guide and target specificity from the mesophilic bacterium Kurthia massiliensis. Nucleic acids research 49, 4054-4065.

Kuzmenko, A., Oguienko, A., Esyunina, D., Yudin, D., Petrova, M., Kudinova, A., Maslova, O., Ninova, M., Ryazansky, S., Leach, D., et al. (2020). DNA targeting and interference by a bacterial Argonaute nuclease. Nature 587, 632-637.

Liu, J., Cvirkaite-Krupovic, V., Baquero, D.P., Yang, Y., Zhang, Q., Shen, Y., and Krupovic, M. (2021a). Virus-induced cell gigantism and asymmetric cell division in archaea. Proceedings of the National Academy of Sciences of the United States of America 118. 
Liu, Q., Guo, X., Xun, G., Li, Z., Chong, Y., Yang, L., Wang, H., Zhang, F., Luo, S., Cui, L., et al. (2021b). Argonaute integrated single-tube PCR system enables supersensitive detection of rare mutations. Nucleic acids research 49, e75.

900 Liu, X., Zhang, Z., Ruan, J., Pan, Y., Magupalli, V.G., Wu, H., and Lieberman, J. (2016).

901 Inflammasome-activated gasdermin $\mathrm{D}$ causes pyroptosis by forming membrane pores. Nature $902 \quad 535,153-158$.

903 Liu, Y., Li, W., Jiang, X., Wang, Y., Zhang, Z., Liu, Q., He, R., Chen, Q., Yang, J., Wang, L., et al. (2021c). A programmable omnipotent Argonaute nuclease from mesophilic bacteria Kurthia massiliensis. Nucleic acids research.

906 Lombard, J., Lopez-Garcia, P., and Moreira, D. (2012). The early evolution of lipid membranes and the three domains of life. Nature reviews Microbiology 10, 507-515.

908 Lopatina, A., Tal, N., and Sorek, R. (2020). Abortive Infection: Bacterial Suicide as an Antiviral Immune Strategy. Annual review of virology 7, 371-384. Ly, J.D., Grubb, D.R., and Lawen, A. (2003). The mitochondrial membrane potential (deltapsi $(m)$ ) in apoptosis; an update. Apoptosis : an international journal on programmed cell 912 death 8, 115-128.

913 Ma, J.B., Ye, K., and Patel, D.J. (2004). Structural basis for overhang-specific small 914 interfering RNA recognition by the PAZ domain. Nature 429, 318-322.

915 Ma, J.B., Yuan, Y.R., Meister, G., Pei, Y., Tuschl, T., and Patel, D.J. (2005). Structural basis 916 for 5'-end-specific recognition of guide RNA by the A. fulgidus Piwi protein. Nature 434, 666917670.

918 Makarova, K.S., Wolf, Y.I., van der Oost, J., and Koonin, E.V. (2009). Prokaryotic homologs 919 of Argonaute proteins are predicted to function as key components of a novel system of 920 defense against mobile genetic elements. Biology direct 4, 29.

921 Meister, G. (2013). Argonaute proteins: functional insights and emerging roles. Nature 922 reviews Genetics 14, 447-459.

923 Mesa-Galloso, H., Pedrera, L., and Ros, U. (2021). Pore-forming proteins: From defense 924 factors to endogenous executors of cell death. Chemistry and physics of lipids 234, 105026. Mestre, M.R., Gonzalez-Delgado, A., Gutierrez-Rus, L.I., Martinez-Abarca, F., and Toro, N. (2020). Systematic prediction of genes functionally associated with bacterial retrons and classification of the encoded tripartite systems. Nucleic acids research 48, 12632-12647. Millman, A., Bernheim, A., Stokar-Avihail, A., Fedorenko, T., Voichek, M., Leavitt, A., Oppenheimer-Shaanan, Y., and Sorek, R. (2020a). Bacterial Retrons Function In Anti-Phage

930 Defense. Cell 183, 1551-1561 e1512.

931 Millman, A., Melamed, S., Amitai, G., and Sorek, R. (2020b). Diversity and classification of 932 cyclic-oligonucleotide-based anti-phage signalling systems. Nature microbiology 5, 1608-1615.

933 Miyoshi, T., Ito, K., Murakami, R., and Uchiumi, T. (2016). Structural basis for the recognition 934 of guide RNA and target DNA heteroduplex by Argonaute. Nature communications 7, 11846.

935 Niewoehner, O., Garcia-Doval, C., Rostol, J.T., Berk, C., Schwede, F., Bigler, L., Hall, J., 936 Marraffini, L.A., and Jinek, M. (2017). Type III CRISPR-Cas systems produce cyclic 937 oligoadenylate second messengers. Nature 548, 543-548.

938 Ofir, G., Herbst, E., Baroz, M., Cohen, D., Millman, A., Doron, S., Tal, N., Malheiro, D.B.A., 939 Malitsky, S., Amitai, G., et al. (2021). Antiviral activity of bacterial TIR domains via immune 940 signalling molecules. Nature 600, 116-120. 
941 Olovnikov, I., Chan, K., Sachidanandam, R., Newman, D.K., and Aravin, A.A. (2013).

942 Bacterial argonaute samples the transcriptome to identify foreign DNA. Molecular cell 51, 943 594-605.

944 Parker, J.S., Roe, S.M., and Barford, D. (2005). Structural insights into mRNA recognition 945 from a PIWI domain-siRNA guide complex. Nature 434, 663-666.

946 Parma, D.H., Snyder, M., Sobolevski, S., Nawroz, M., Brody, E., and Gold, L. (1992). The 947 Rex system of bacteriophage lambda: tolerance and altruistic cell death. Genes \&

948 development 6, 497-510.

949 Peng, N., Deng, L., Mei, Y., Jiang, D., Hu, Y., Awayez, M., Liang, Y., and She, Q. (2012). A 950 synthetic arabinose-inducible promoter confers high levels of recombinant protein expression 951 in hyperthermophilic archaeon Sulfolobus islandicus. Applied and environmental microbiology 952 78, 5630-5637.

953 Prangishvili, D., Forterre, P., and Garrett, R.A. (2006). Viruses of the Archaea: a unifying view. 954 Nature reviews Microbiology 4, 837-848.

955 Rastadter, K., Wurm, D.J., Spadiut, O., and Quehenberger, J. (2020). The Cell Membrane of 956 Sulfolobus spp.-Homeoviscous Adaption and Biotechnological Applications. International 957 journal of molecular sciences 21.

958 Reno, M.L., Held, N.L., Fields, C.J., Burke, P.V., and Whitaker, R.J. (2009). Biogeography of 959 the Sulfolobus islandicus pan-genome. Proceedings of the National Academy of Sciences of 960 the United States of America 106, 8605-8610.

961 Ryazansky, S., Kulbachinskiy, A., and Aravin, A.A. (2018). The Expanded Universe of 962 Prokaryotic Argonaute Proteins. mBio 9.

963 Shah, S.A., Alkhnbashi, O.S., Behler, J., Han, W., She, Q., Hess, W.R., Garrett, R.A., and 964 Backofen, R. (2019). Comprehensive search for accessory proteins encoded with archaeal 965 and bacterial type III CRISPR-cas gene cassettes reveals 39 new cas gene families. RNA 966 biology 16, 530-542.

967 Shi, J., Gao, W., and Shao, F. (2017). Pyroptosis: Gasdermin-Mediated Programmed 968 Necrotic Cell Death. Trends in biochemical sciences 42, 245-254.

969 Shmakov, S.A., Makarova, K.S., Wolf, Y.I., Severinov, K.V., and Koonin, E.V. (2018).

970 Systematic prediction of genes functionally linked to CRISPR-Cas systems by gene 971 neighborhood analysis. Proceedings of the National Academy of Sciences of the United 972 States of America 115, E5307-E5316.

973 Soding, J., Biegert, A., and Lupas, A.N. (2005). The HHpred interactive server for protein 974 homology detection and structure prediction. Nucleic acids research 33, W244-248.

975 Song, J.J., Smith, S.K., Hannon, G.J., and Joshua-Tor, L. (2004). Crystal structure of 976 Argonaute and its implications for RISC slicer activity. Science 305, 1434-1437.

977 Swarts, D.C., Hegge, J.W., Hinojo, I., Shiimori, M., Ellis, M.A., Dumrongkulraksa, J., Terns, 978 R.M., Terns, M.P., and van der Oost, J. (2015). Argonaute of the archaeon Pyrococcus 979 furiosus is a DNA-guided nuclease that targets cognate DNA. Nucleic acids research 43, $980 \quad 5120-5129$.

981 Swarts, D.C., Jore, M.M., Westra, E.R., Zhu, Y., Janssen, J.H., Snijders, A.P., Wang, Y., 982 Patel, D.J., Berenguer, J., Brouns, S.J.J., et al. (2014a). DNA-guided DNA interference by a 983 prokaryotic Argonaute. Nature 507, 258-261.

984 Swarts, D.C., Makarova, K., Wang, Y., Nakanishi, K., Ketting, R.F., Koonin, E.V., Patel, D.J., 985 and van der Oost, J. (2014b). The evolutionary journey of Argonaute proteins. Nature 986 structural \& molecular biology 21, 743-753. 
987 Swarts, D.C., Szczepaniak, M., Sheng, G., Chandradoss, S.D., Zhu, Y., Timmers, E.M.,

988 Zhang, Y., Zhao, H., Lou, J., Wang, Y., et al. (2017). Autonomous Generation and Loading of 989 DNA Guides by Bacterial Argonaute. Molecular cell 65, 985-998 e986.

990 Uldahl, K.B., Jensen, S.B., Bhoobalan-Chitty, Y., Martinez-Alvarez, L., Papathanasiou, P., 991 and Peng, X. (2016). Life Cycle Characterization of Sulfolobus Monocaudavirus 1, an 992 Extremophilic Spindle-Shaped Virus with Extracellular Tail Development. Journal of virology 993 90, 5693-5699.

994 van Beljouw, S.P.B., Haagsma, A.C., Rodriguez-Molina, A., van den Berg, D.F., Vink, J.N.A., 995 and Brouns, S.J.J. (2021). The gRAMP CRISPR-Cas effector is an RNA endonuclease 996 complexed with a caspase-like peptidase. Science 373, 1349-1353.

997 VanderWal, A., Park, J., Polevoda, B., Kellogg, E., and Connell, M. (2021). CRISPR-Csx28 998 forms a Cas13b-activated membrane pore required for robust CRISPR-Cas adaptive 999 immunity. BioRxiv.

1000 Wang, H., Sun, L., Su, L., Rizo, J., Liu, L., Wang, L.F., Wang, F.S., and Wang, X. (2014). 1001 Mixed lineage kinase domain-like protein MLKL causes necrotic membrane disruption upon 1002 phosphorylation by RIP3. Molecular cell 54, 133-146.

1003 Waterhouse, A.M., Procter, J.B., Martin, D.M., Clamp, M., and Barton, G.J. (2009). Jalview 1004 Version 2--a multiple sequence alignment editor and analysis workbench. Bioinformatics 25, 1005 1189-1191.

1006 Westra, E.R., van Erp, P.B., Kunne, T., Wong, S.P., Staals, R.H., Seegers, C.L., Bollen, S., Jore, M.M., Semenova, E., Severinov, K., et al. (2012). CRISPR immunity relies on the 1008 consecutive binding and degradation of negatively supercoiled invader DNA by Cascade and 1009 Cas3. Molecular cell 46, 595-605.

1010 Willkomm, S., Oellig, C.A., Zander, A., Restle, T., Keegan, R., Grohmann, D., and Schneider, 1011 S. (2017). Structural and mechanistic insights into an archaeal DNA-guided Argonaute protein. 1012 Nature microbiology 2, 17035.

1013 Zander, A., Willkomm, S., Ofer, S., van Wolferen, M., Egert, L., Buchmeier, S., Stockl, S., 1014 Tinnefeld, P., Schneider, S., Klingl, A., et al. (2017). Guide-independent DNA cleavage by 1015 archaeal Argonaute from Methanocaldococcus jannaschii. Nature microbiology 2, 17034.

1016 Zhang, C., Phillips, A.P.R., Wipfler, R.L., Olsen, G.J., and Whitaker, R.J. (2018). The 1017 essential genome of the crenarchaeal model Sulfolobus islandicus. Nature communications 9 , 10184908.

1019 Zhao, R., Yang, Y., Yang, K., and Han, W. (2021). Expression, purification, and 1020 characterization of a membrane-associated cyclic oligo-adenylate degrader from Sulfolobus 1021 islandicus. STAR protocols 2, 100299. 
A

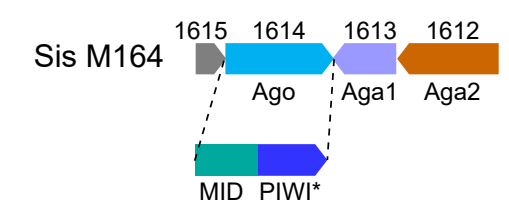

B

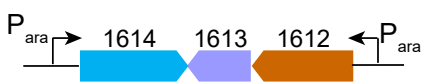

Ago-1-2

C

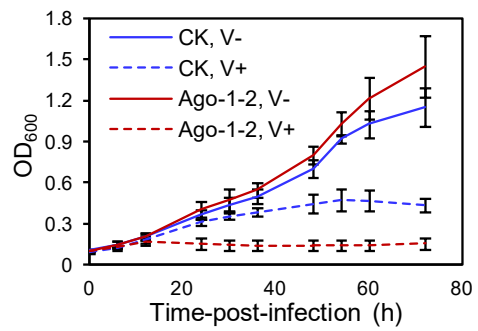

D

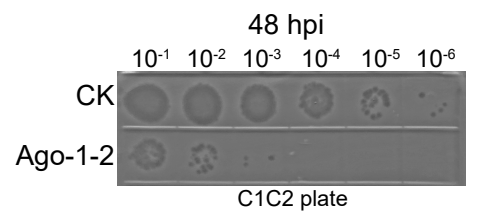

E

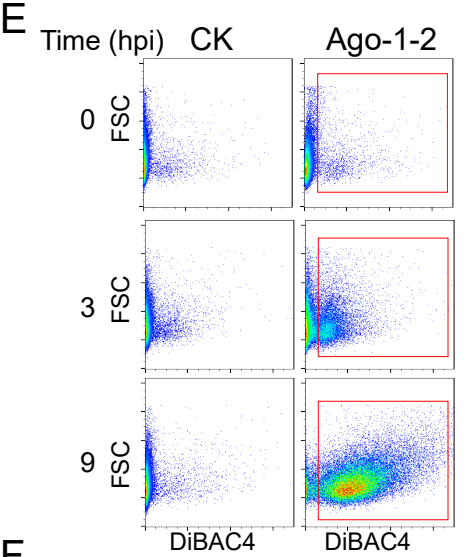

F

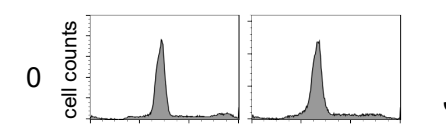

G
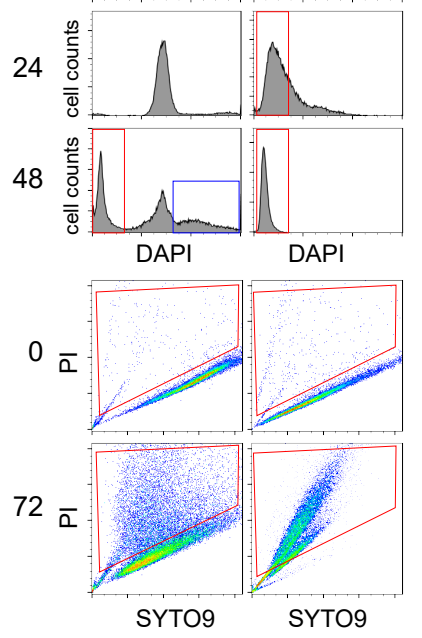

$\mathrm{H}$

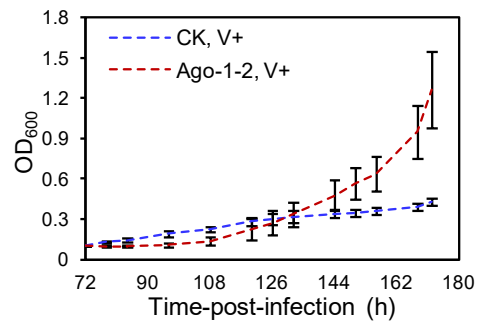

I

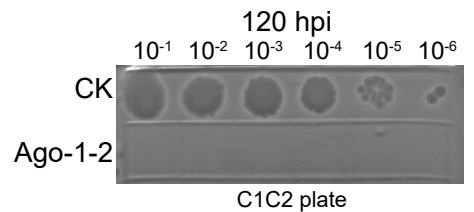

$\mathrm{J}$

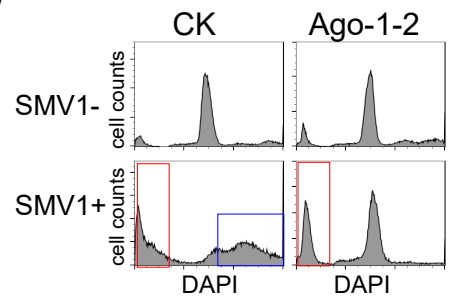


A

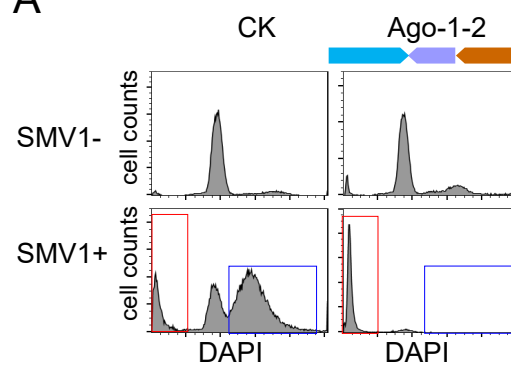

C

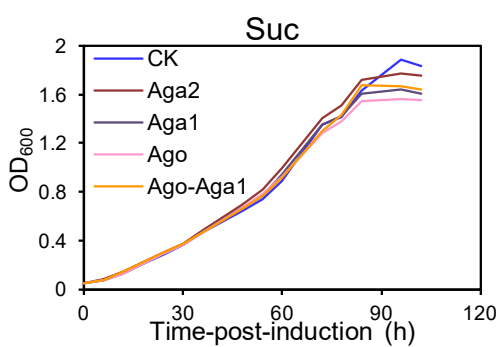

Figure 2
B
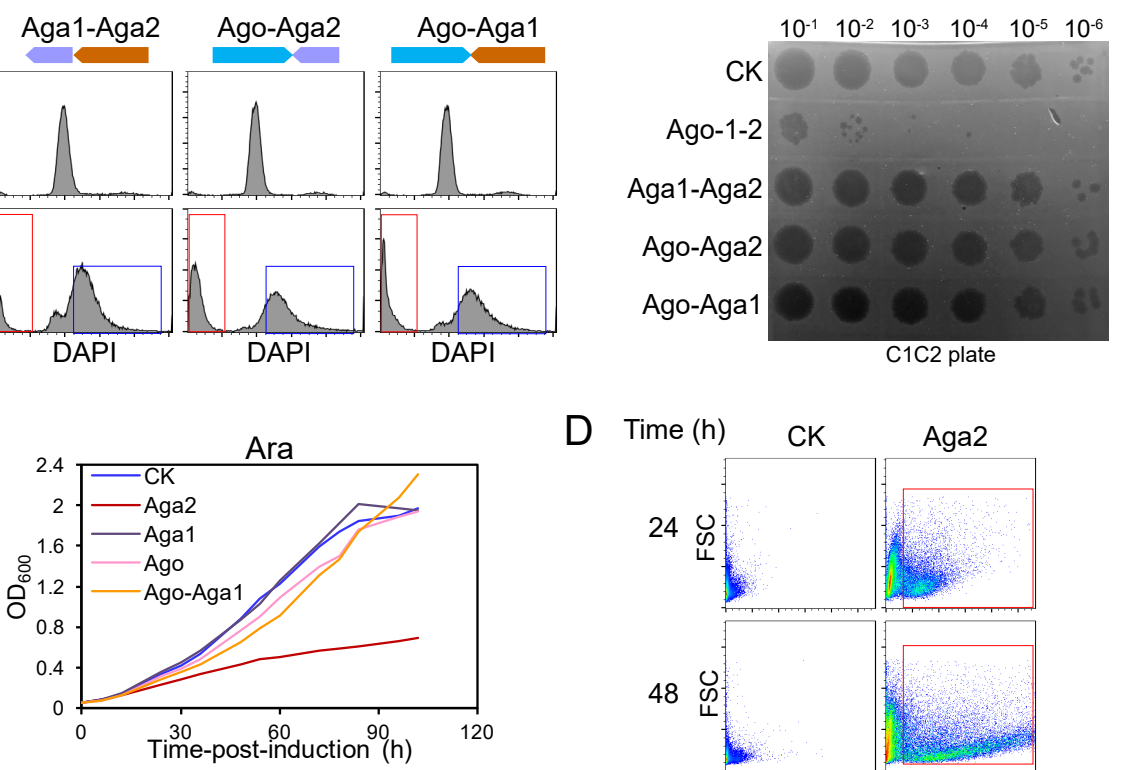

D Time (h)

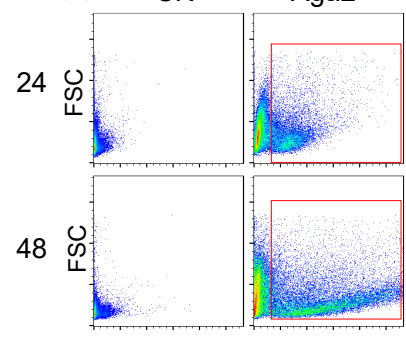

DiBAC4 
A

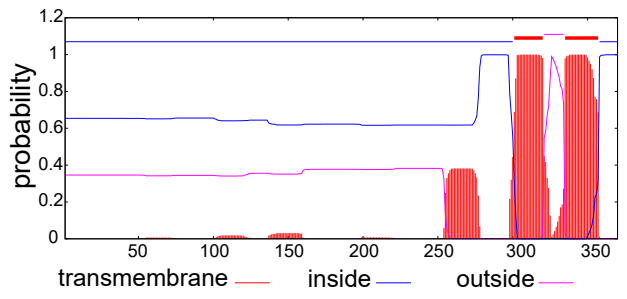

B

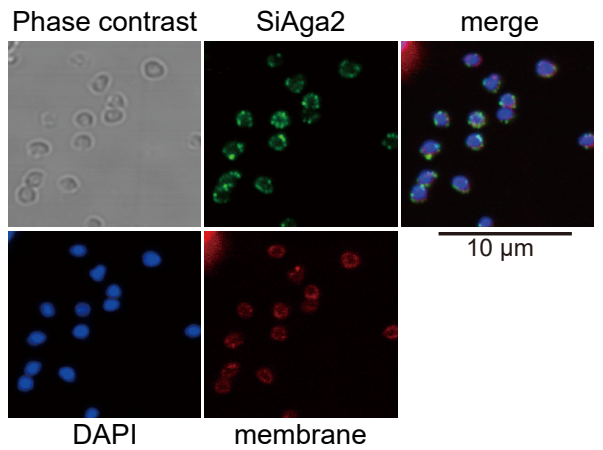

C

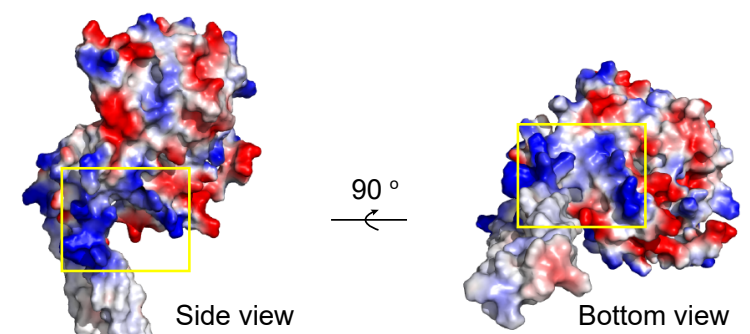

D
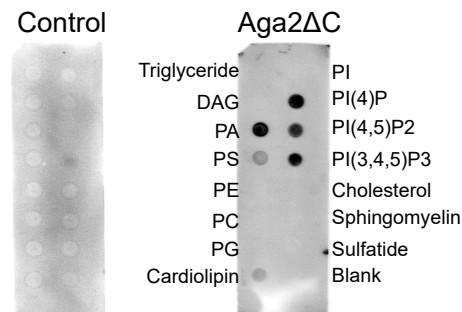

Membrane strip

Membrane strip

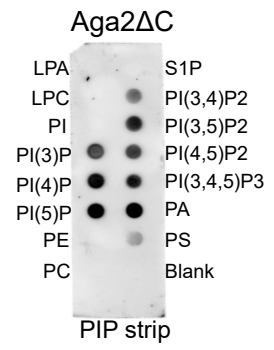

Figure 3 
A

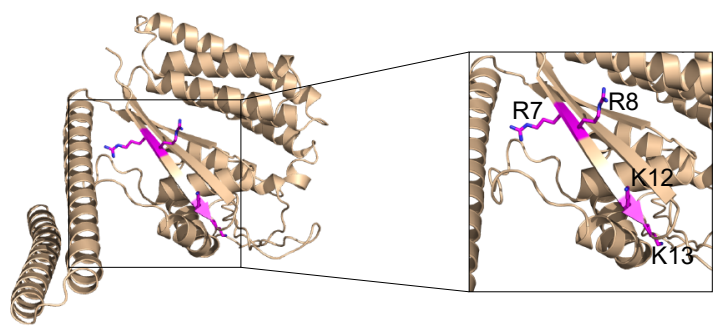

B

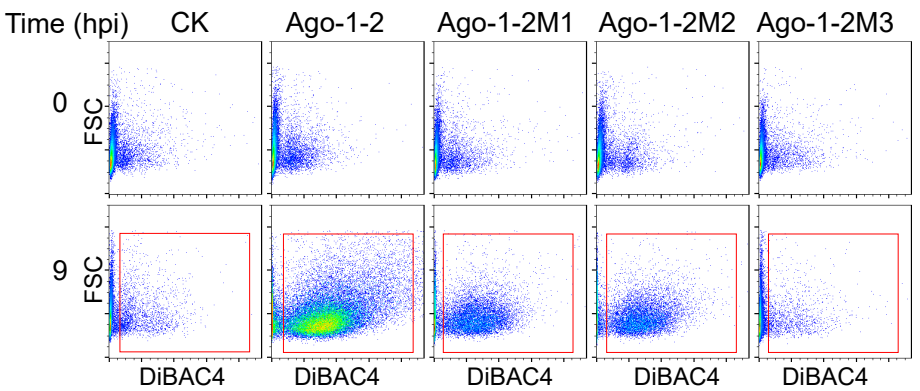

C

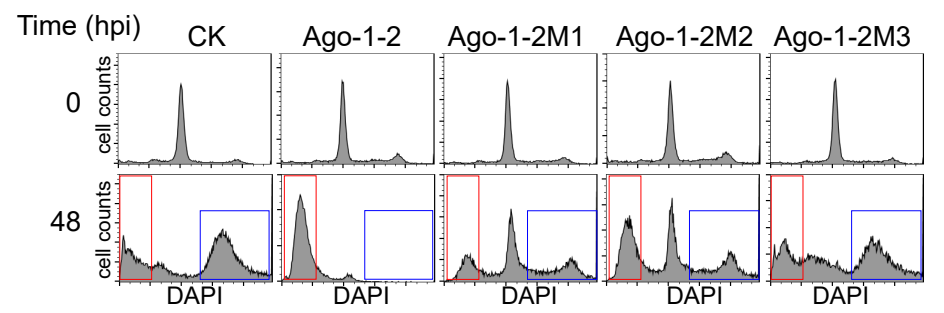

D

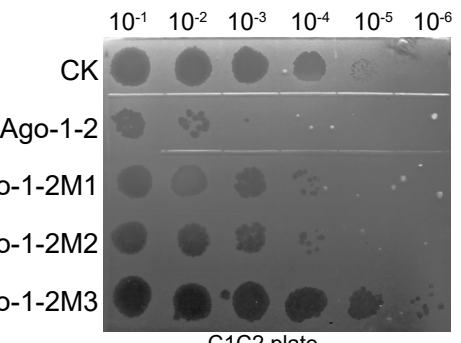

\section{C1C2 plate}

E

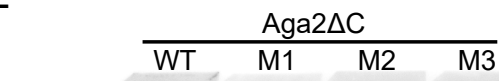

Triglyceride

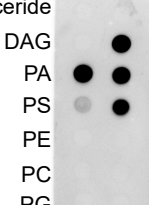

Cardiolipin

PI

$\mathrm{PI}(4) \mathrm{P}$

$\mathrm{PI}(4,5) \mathrm{P} 2$

$\mathrm{PI}(3,4,5) \mathrm{P} 3$

Cholesterol

Sphingomyelin

Sulfatide

Blank

Membrane strip 

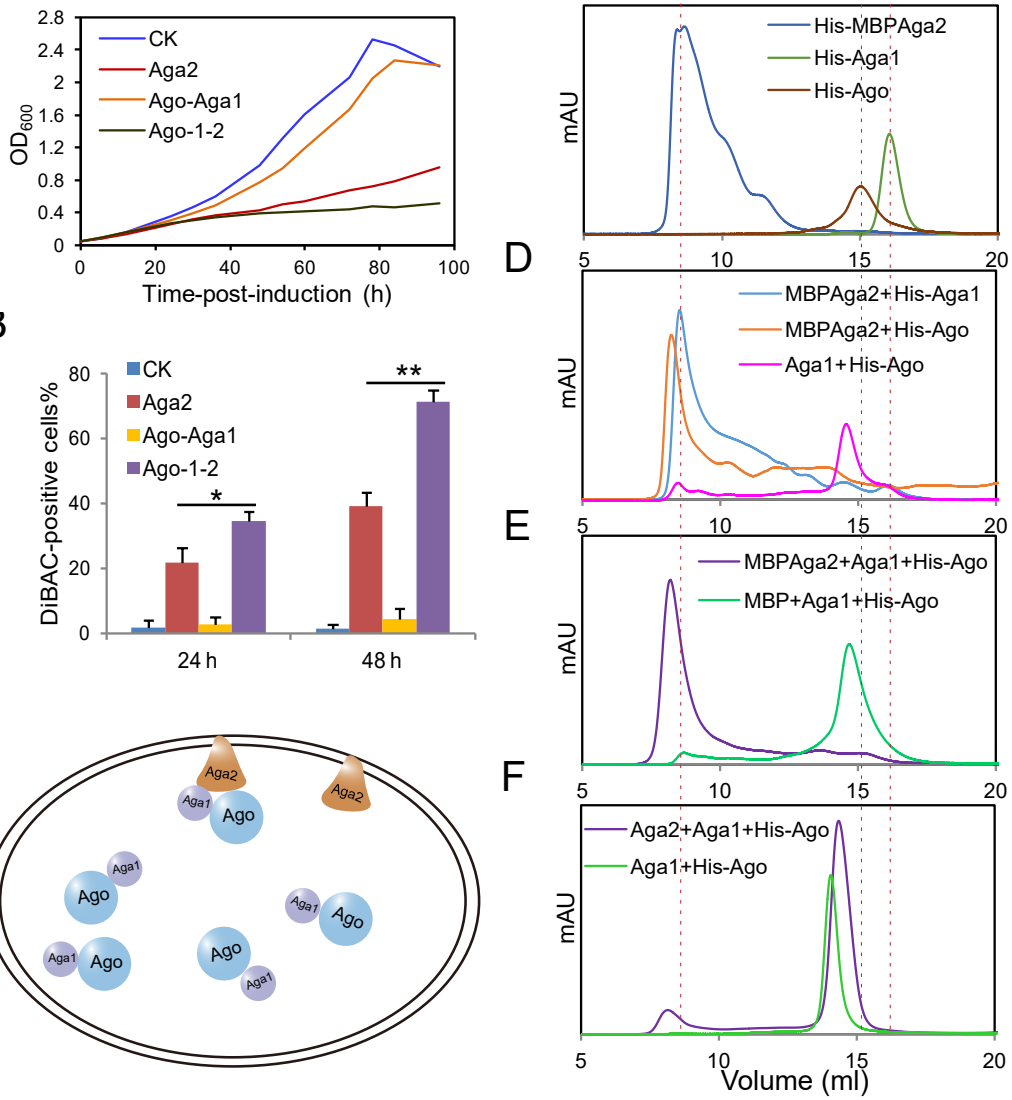

Figure 5 
A

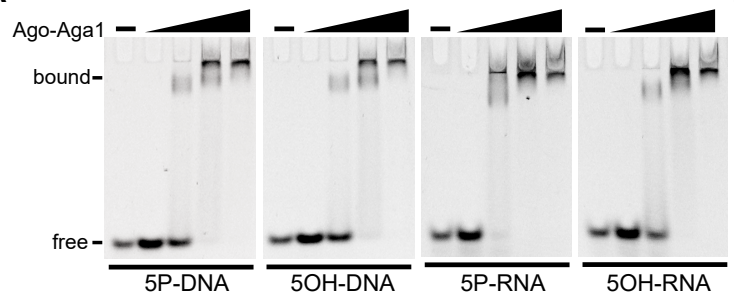

B

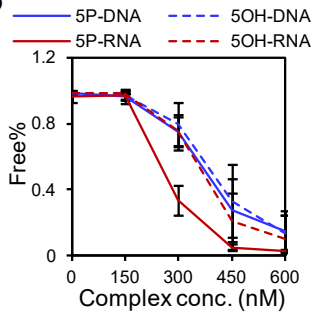

C
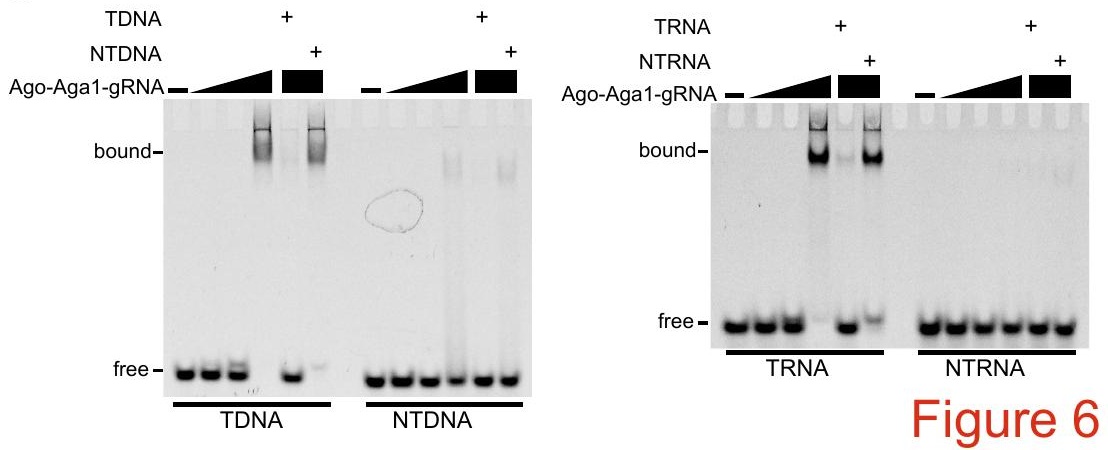


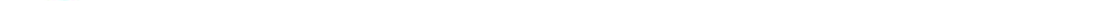

